Journal Of Physical Chemistry C

August 2016, Volume 120 Issue 32 Pages 18158-18166

http://dx.doi.org/10.1021/acs.jpcc.6b06486

http://archimer.ifremer.fr/doc/00350/46139/

(c) 2016 American Chemical Society

\title{
Evidence of the Grafting Mechanisms of Diazonium Salts on Gold Nanostructures
}

\author{
Betelu Stéphanie ${ }^{1,2,{ }^{*}}$, Tijunelyte Inga ${ }^{3}$, Boubekeur-Lecaque Leïla ${ }^{4}$, Ignatiadis loannis ${ }^{1,2}$, \\ Ibrahim Joyce ${ }^{5}$, Gaboreau Stéphane ${ }^{1,2}$, Berho Catherine ${ }^{1,2}$, Toury Timothée ${ }^{4}$, Guenin Erwann ${ }^{3}$, \\ Lidgi-Guigui Nathalie ${ }^{3}$, Félidj Nordin ${ }^{4}$, Rinnert Emmanuel ${ }^{6}$, Lamy De La Chapelle Marc ${ }^{3}$
}

${ }^{1}$ Bur Rech Geol \& Minieres, Water Environm \& Ecotechnol Div, F-45060 Orleans 02, France.

2 Bur Rech Geol \& Minieres, Lab Direct, F-45060 Orleans 02, France.

${ }^{3}$ Univ Paris 13, Sorbonne Paris Cite, CNRS, Lab CSPBAT,UMR7244, 74 Rue Marcel Cachin, F-93017 Bobigny, France.

${ }^{4}$ Univ Paris Diderot, Sorbonne Paris Cite, CNRS, ITODYS,UMR 7086, 15 Rue J-A de Baif, F-75205

Paris 13, France.

${ }^{5}$ Univ Technol Troyes, 12 Rue Marie Curie, F-10000 Troyes, France.

${ }^{6}$ IFREMER, Brittany Ctr, CS10070, Measurements Detect \& Sensors Lab, F-29280 Plouzane, France.

*Corresponding author : Stéphanie Betelu, email address : s.betelu@brgm.fr

\begin{abstract}
:
Gold nanostructures (GNS) were chemically functionalized using four different diazonium salts: benzene-diazonium-tetrafluoroborate (DS), 4-decylbenzene-diazonium-tetrafluoroborate (DS-C10H21), 4-carboxybenzene-diazonium-tetrafluoroborate (DS-COOH), and 4-(aminoethyl)-benzene-diazoniumtetrafluoroborate (DS- $(\mathrm{CH} 2)(2) \mathrm{NH} 2)$. Effective chemical grafting on GNS was shown by surfaceenhanced Raman spectroscopy (SERS); aromatic ring deformations in the range of $1570-1591 \mathrm{~cm}(-1)$ are of particular interest. The very strong band observed around $1075 \mathrm{~cm}(-1)$, related to $\mathrm{CH}$ in-plane bending for mono- and para-substituted benzenes (coupled with ring- $\mathrm{N}$ stretching mode), provided further irrefutable evidence of the grafting. SERS enhancement of these two bands ascertains the perpendicular orientation of the aromatic rings on the GNS. X-ray photoelectron spectroscopy (XPS) analyses of chemically grafted flat gold surfaces suggest azophenyl radical pathways when using DS, DS-(CH2)(2)-NH2, or DS-C10H21. It was shown that coating at the interface is the result of a Au-N covalent bond; growth of the layers is via $\mathrm{N}=\mathrm{N}$. These XPS results agree with those provided by SERS without excluding the aryl radical pathways. For DS-COOH, the results provided by SERS, XPS, and density functional theory calculations show (i) effective chemical grafting of the GNS via a covalent bond between gold and carboxylate forms and (ii) growth via multilayers in the meta position between aromatic rings through either $\mathrm{N}=\mathrm{N}$ or $\mathrm{C}-\mathrm{C}$ bonds.
\end{abstract}




\section{Graphical abstract}

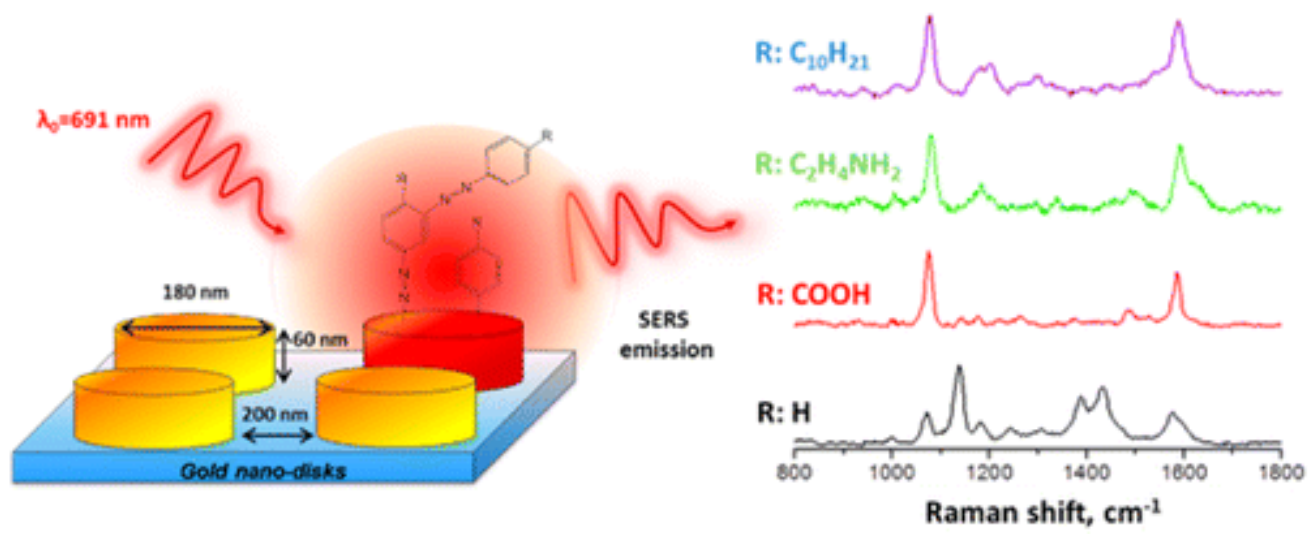




\section{Introduction}

Thanks to (i) the improvement of electronics that led to miniaturize the Raman spectrometer ${ }^{1}$,

(ii) the great progress in nano-scale technology of nano-sensors ${ }^{2-3}$, and (iii) surface chemistry using self-assembled monolayers (SAMs), Surface Enhanced Raman Spectroscopy (SERS) has become a promising tool for sensing ${ }^{3-15}$.

Among the investigated strategies for the development of robust sensing devices ${ }^{16-18}$, surface functionalization via diazonium salt has been selected as one of the most powerful alternatives to SAMs. Immobilization of aryldiazonium allows the grafting of stable organic layers, bearing a wide range of functional groups. The grafting can be done by chemical (spontaneous grafting) ${ }^{19-22}$, electrochemical ${ }^{23-25}$, or physical ${ }^{26}$ methods. According to the literature ${ }^{19,21}$, such grafting involves reductive electron transfer from the conductive or semiconductive surface to a diazonium salt together with the cleavage of dinitrogen ${ }^{27}$. This phenomenon leads to the generation of aryl radicals, followed by the binding of these radicals to the surface via carbon-surface covalent bonds (Fig. 1A) ${ }^{28}$. To demonstrate such a chemical mechanism, the SERS technique has been used for ascertaining the existence of covalent bonds between the gold surface and the aromatic ring ${ }^{22}$. Aryl radicals can also bind to aromatic rings already attached to the conductive surface (Fig. 1B) ${ }^{28}$. The thickness of the coating can vary from a monolayer (thickness $\sim 1 \mathrm{~nm}$ ) to 5 -nm-thick multilayers ${ }^{29}$. In addition to these two pathways, the formation of azophenyl radicals and their direct bond either to the conductive surface (Fig. 1C) ${ }^{30}$, or to an aromatic ring already attached to the conductive surface (Fig. 1D or $1 \mathrm{E})^{31-32}$, has been reported as well. 


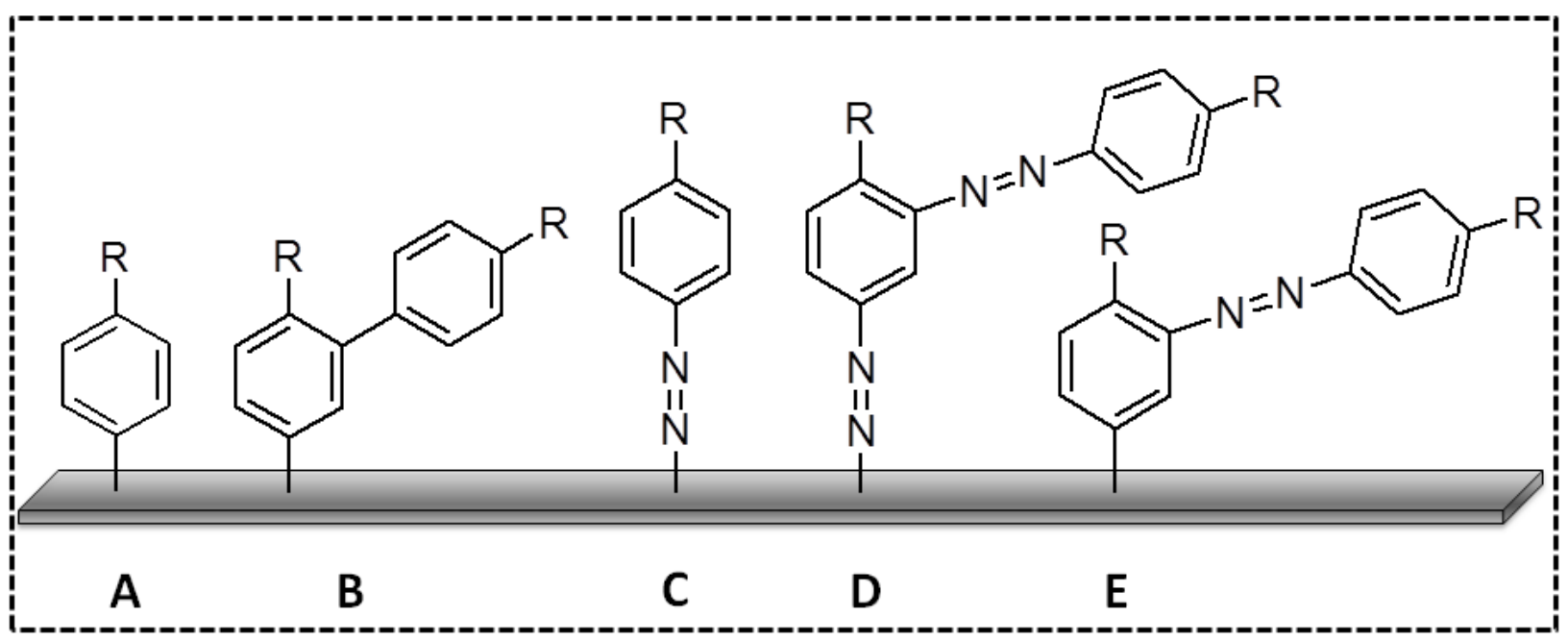

Figure 1: Schematic illustration of the different pathways for aryl derivatives grafting onto conductive surfaces.

The phenomena corresponding to Figs. 1C, D or E, were essentially shown by X-ray photoelectron spectroscopy (XPS), due to the presence of a peak at $400 \mathrm{eV}$ in the nitrogen $1 \mathrm{~s}$ core-level spectral region. Belanger and co-workers were the first to claim the presence of azo groups on carbon-based substrates functionalized by electrochemistry ${ }^{32}$ and by spontaneous grafting ${ }^{33}$, even for the creation of monolayers ${ }^{33}$. This last observation was explained by the coupling of diazonium cations with carbon surfaces having phenolic-type oxygenated functionalities to form an azo bond. In 2012, Ricci et al. ${ }^{30}$ provided evidence of the formation of an azo bond on gold substrates after the electroreduction of carboxy-benzene-diazonium salts, particularly by using 4-amino (2,3,5,6-tetrafluoro)-carboxy-benzene-diazonium salts, which are likely to form monolayers due to hindrance onto the 3- and 5-positions on the phenyl ring ${ }^{34}$. According to these authors, formation of the azo bond on gold was shown by the presence of an azo stretching mode $(\mathrm{uN}=\mathrm{N})$, observed at $1392 \mathrm{~cm}^{-1}$ by Polarization Modulation-Infrared Reflection-Adsorption Spectroscopy (PM-IRRAS) ${ }^{35}$. Also in 2012, Mesnage et al. ${ }^{36}$ provided 
evidence of the formation of an azo bond on gold substrates that were spontaneously functionalized by using $\mathrm{NO}_{2}, \mathrm{Br}$ - and $\mathrm{CH}_{3} \mathrm{~S}$-diazonium salts. The $\mathrm{Au}-\mathrm{N}$ bond was further shown by XPS due to the presence of a peak containing gold nitrides at $398.1 \mathrm{eV}$.

Whatever the pathway, the robustness of diazonium-salt-based grafted layer(s) had already been demonstrated ${ }^{24,37-38}$. However, in order to apply a diazonium-salt-based sensor for molecular sensing by SERS, exhaustive surface analysis and vibrational-mode identification is of prime importance. In this context, tailoring the surface chemistry of the SERS sensors is one of the key factors for successful applications in sensing.

Our study provides a SERS characterization of gold nanostructures (GNS) that were chemically functionalized by using four different diazonium salts. Compared to silver ${ }^{39}$, gold was preferred for the development of a robust sensor in aqueous media, especially in seawater. SERS substrates were fabricated by electron-beam lithography (EBL), one of the most appropriate approaches for controlling the geometrical parameters of the optical support's sensitive parts (size, shape and arrangement of GNS), and for preparing well defined and reproducible nanostructured materials ${ }^{40}$. Four diazonium salts were selected for developing "long-life" robust SERS sensors:

- benzene-diazonium-tetrafluoroborate (DS), which is the simplest salt and has been chosen as a reference and because of the availability of an aromatic cycle for $\pi$ - $\pi$ stacking;

- 4-decylbenzene-diazonium-tetrafluoroborate $\left(\mathrm{DS}-\mathrm{C}_{10} \mathrm{H}_{21}\right)$, which has a long non-polar alkyl chain with a lipophilic and hydrophobic character for pre-concentrating non-polar molecules;

- 4-carboxybenzene-diazonium-tetrafluoroborate (DS-COOH) and 4-(aminoethyl)-benzenediazonium-tetrafluoroborate (DS- $\left.\left(\mathrm{CH}_{2}\right)_{2} \mathrm{NH}_{2}\right)$, which can both be used for biomolecule 
coupling thanks to the presence of $\mathrm{COOH}$ and $\mathrm{NH}_{2}$ groups, or for the pre-concentration of polar molecules.

The effective chemical grafting was examined by comparing Raman spectra obtained for each synthesized diazonium salt with the SERS spectra of the phenyl derivatives-based GNS. Xray photoelectron spectroscopy (XPS) on grafted flat gold substrates examined and identified the nature of the interface between the GNS and the organic coating. Density Functional Theory (DFT) calculations on the SERS spectra of DS-COOH-based GNS provided a better insight into the bands assignment, and confirmed the SERS-spectra and XPS interpretations.

\section{Materials and methods}

\section{Material and Reagents}

Sodium nitrite $\left(\mathrm{NaNO}_{2}\right)$, tetrafluoroboric acid $\left(\mathrm{HBF}_{4}\right)$, diethyl ether $(>98 \%$, ACS reagent), aniline, 4-docyl-aniline, 4-aminobenzoic acid and 4-(2-aminoethyl)-aniline were purchased from Sigma Aldrich Chimie S.a.r.l (St. Quentin Fallavier, 38297 France). Suprapur sulfuric acid $\mathrm{H}_{2} \mathrm{SO}_{4}(95-98 \%)$ was supplied by JT Baker.

\section{Diazonium salt synthesis}

The synthesis of diazonium salts was done according to the reaction between aryl amines and sodium nitrile at $0{ }^{\circ} \mathrm{C}^{41}$. Briefly, $4 \times 10^{-3} \mathrm{~mol} \mathrm{~L}^{-1}$ of each amine was dissolved in an $\mathrm{HBF}_{4}$ acid solution. This solution was allowed to cool for $15 \mathrm{~min}$, and for 1 hour for the mixture containing the 4-docyl-aniline. Sodium nitrite $\left(4.3 \times 10^{-3} \mathrm{~mol}\right.$ dissolved in milliQ water $)$ was added drop-bydrop to the acidic amine solution while stirring. The mixture was allowed to react for 2 hours, 
and for 96 hours for the mixture containing 4-docyl-aniline. A precipitate appeared in the solution which was filtered, rinsed with glacial ether, and purified. The salts were then dried and kept at $-20{ }^{\circ} \mathrm{C}$. The successful synthesis of the four diazonium salts with a high production rate was confirmed by NMR ${ }^{41}$.

\section{SERS substrates}

Gold was chosen for its chemical stability and as a robust material for the elaboration of nanostructures on borosilicate-glass substrates, paving the way for its use in all aquatic environments. Electron Beam Lithography (EBL) and lift-off techniques were used to fabricate the nanostructures of desired shape, size and arrangement ${ }^{40}$, ensuring control of the geometrical parameters for reproducible substrates. The produced GNS were nano-cylinder arrays in patterns $(50 \mu \mathrm{m} \times 50 \mu \mathrm{m})$ with diameters of $180 \mathrm{~nm}$. Their height was set at $60 \mathrm{~nm}$ evaporated on $3 \mathrm{~nm}$ of chromium as an adhesive layer. The gap between nano-cylinders from edge to edge was kept constant at $200 \mathrm{~nm}$ in order to avoid any near-field coupling.

Prior to any experiment, the GNS were cleaned using UV-Ozone (PSD-UV - Benchtop UV-Ozone Cleaner, Novascan) for $30 \mathrm{~min}$. Substrates were then rinsed four times by immersion in milliQ water (10 min) and then in ethanol ( $\geq 99.8 \%$ (Fluka)) (10 min).

\section{Surface functionalization}

Chemical grafting was used to functionalize the GNS for SERS-based surface investigation (Fig. 2). For this purpose, SERS substrates were immersed in $10 \mathrm{~mL}$ solution of the diazonium

salt $\left(10^{-3} \mathrm{~mol} \mathrm{~L}^{-1}\right)$ dissolved in $\mathrm{H}_{2} \mathrm{SO}_{4}\left(10^{-3}\right.$ mol L $\left.{ }^{-1}\right)$ during 12 hours at $4{ }^{\circ} \mathrm{C}$ under mild stirring (orbital stirring table). They were then rinsed 3 times by immersion into milliQ water $(10 \mathrm{~mL})$ for $10 \mathrm{~min}$ and dried under nitrogen. 


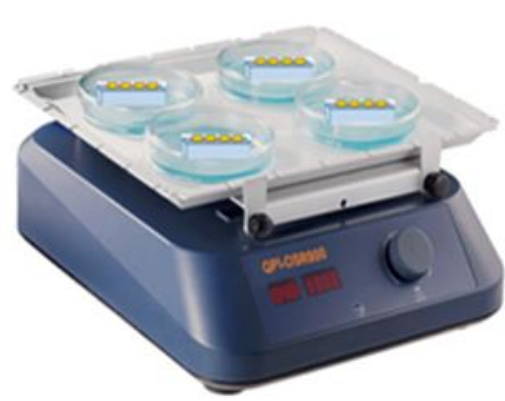

$1 \mathrm{mM}$ of DS in $10 \mathrm{mM}$ of $\mathrm{H}_{2} \mathrm{SO}_{4}$. Incubation for $12 \mathrm{~h}$ at $4^{\circ} \mathrm{C}$

Figure 2: Illustration of the chemical grafting of GNS using four different diazonium salts.

Flat gold substrates were functionalized in the same way. Once grafted, the gold substrates were profusely rinsed with milliQ water, sonicated for 10 min and stored in milliQ water.

\section{Optical measurements}

Raman measurements were performed on synthesized diazonium salts using a $691 \mathrm{~nm}$ excitation line of a thorium-argon (Th-Ar) laser with a LabRam HR800 (Horiba Scientific SAS). In both cases, SERS measurements were done in backscattering geometry with a 100x objective (Numerical aperture of 0.9 ). Spectral resolutions of less than $2 \mathrm{~cm}^{-1}$ were obtained with the LabRam HR800 spectrometer. The laser power density as well as the accumulation time and number of repetitions were varying in order to obtain relevant signal-to-noise ratios.

In agreement with the literature, the best enhancement factor (through LSP resonance, LSPR) depends strongly on the nano-particle size and shape ${ }^{42-43}$, and on the excitation wavelength $19,42,44-46$. In this study, the SERS experiments were conducted by using $180 \mathrm{~nm}$ nano-cylinders, which showed the best enhancement factor for $691 \mathrm{~nm}$. 


\section{XPS measurements}

XPS spectra were recorded with a Thermo VG Scientific ESCALAB 250 system fitted with a microfocused, monochromatic Al Ka X-ray source $(\mathrm{h} v=1486.6 \mathrm{eV}$; spot size $=650 \mu \mathrm{m}$; power $=15 \mathrm{kV} \times 200 \mathrm{~W}$ ). Pass energy was set at 150 and $40 \mathrm{eV}$ for the survey and the narrow regions, respectively. An electron flood gun was used, under a $2 \times 10^{-8}$ mbar partial pressure of argon, for static charge compensation. These conditions resulted in a negative, but uniform, static charge.

\section{Computational details}

All calculations were carried out using the Gaussian 09 suite of programs ${ }^{47}$, using the B3LYP exchange and correlation functional ${ }^{48-49}$ along with the $6-311++\mathrm{G}(\mathrm{d}, \mathrm{p})$ basis set for all atoms, but gold ${ }^{50-51}$. The LANL2DZ basis set, consisting of Effective Core Potential (ECP) and double$\zeta$ quality functions for valence electrons, was used for $\mathrm{Au}^{52}$. The structures were optimized without symmetry constraints. The vibrational frequencies and normal modes were calculated within the harmonic approximation, and a scaling factor of 0.976 was chosen on the basis of previously published work ${ }^{53}$.

\section{Results and Discussion}

Four diazonium salts were selected and the GNS coatings were examined by SERS. In order to define the nature of the interface between the GNS and the coatings, flat gold surfaces were also functionalized under the same conditions and analyzed by XPS. Finally, DFT modeling of SERS spectra of DS-COOH-based GNS served to support both SERS and XPS measurements. 


\section{Raman and SERS Investigations}

We first focus on the Raman and SERS results. Figures 3, 4, 5 and 6 present the Raman and SERS spectra for the four synthesized diazonium salts and the corresponding functionalized GNS. The wave-numbers of important peaks are reported in Table 1 and their assignments were provided from literature data ${ }^{54-56}$. Please note that the whole characterization of phenyl derivatives was already examined by Raman spectroscopy ${ }^{41}$. For a better understanding, the Raman spectra obtained for both primary amines and their corresponding synthesized diazonium salts, are compared on Figures S1, S2, S3 and S4 (Supplementary Information).

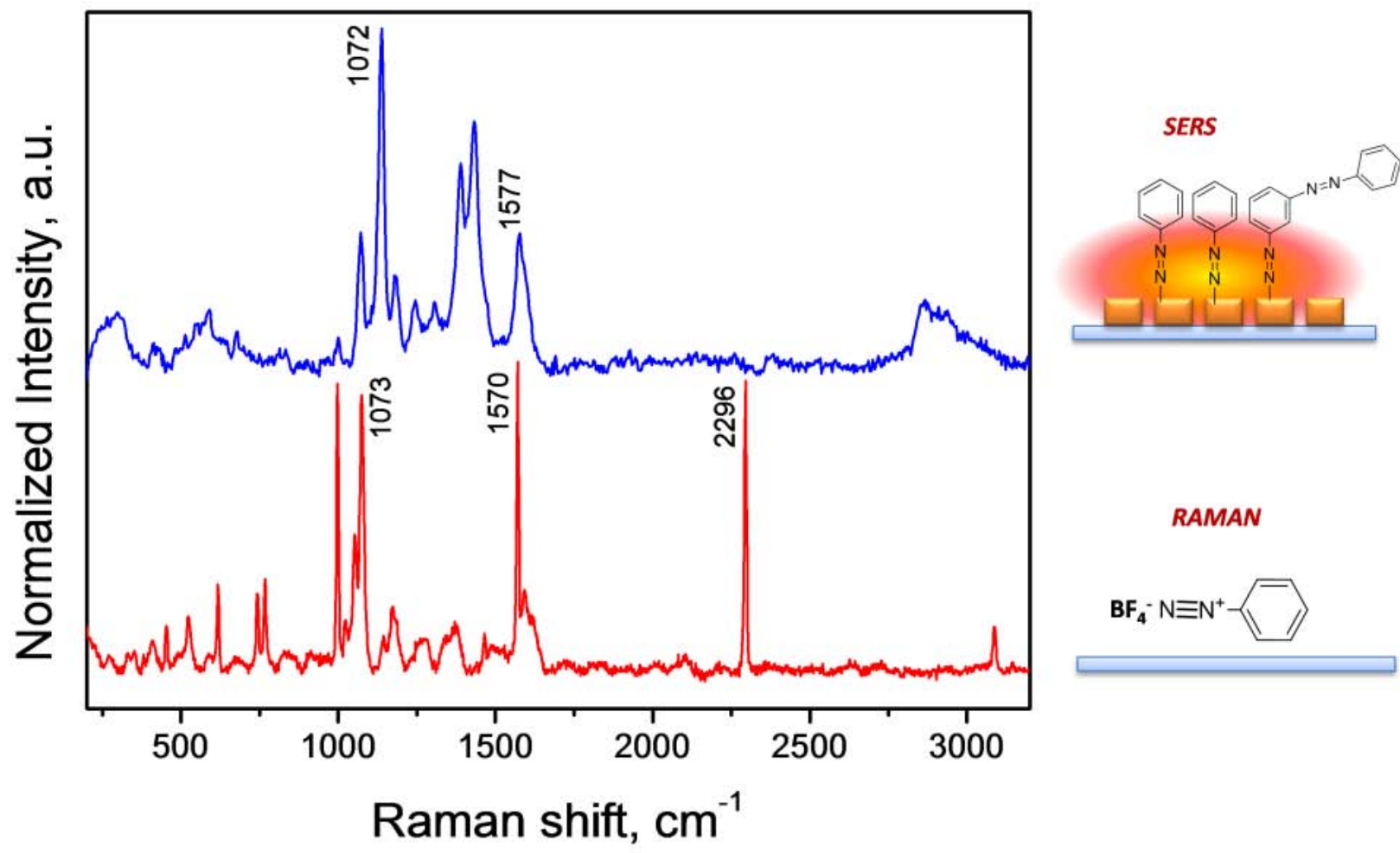

Figure 3: Raman spectrum of DS (red) and SERS spectrum of the DS-based GNS (blue). Each spectrum was normalized to its maximum intensity. Raman and SERS experiments were conducted at $691 \mathrm{~nm}$. SERS experiments used nano-cylinders with a diameter of $180 \mathrm{~nm}$. 


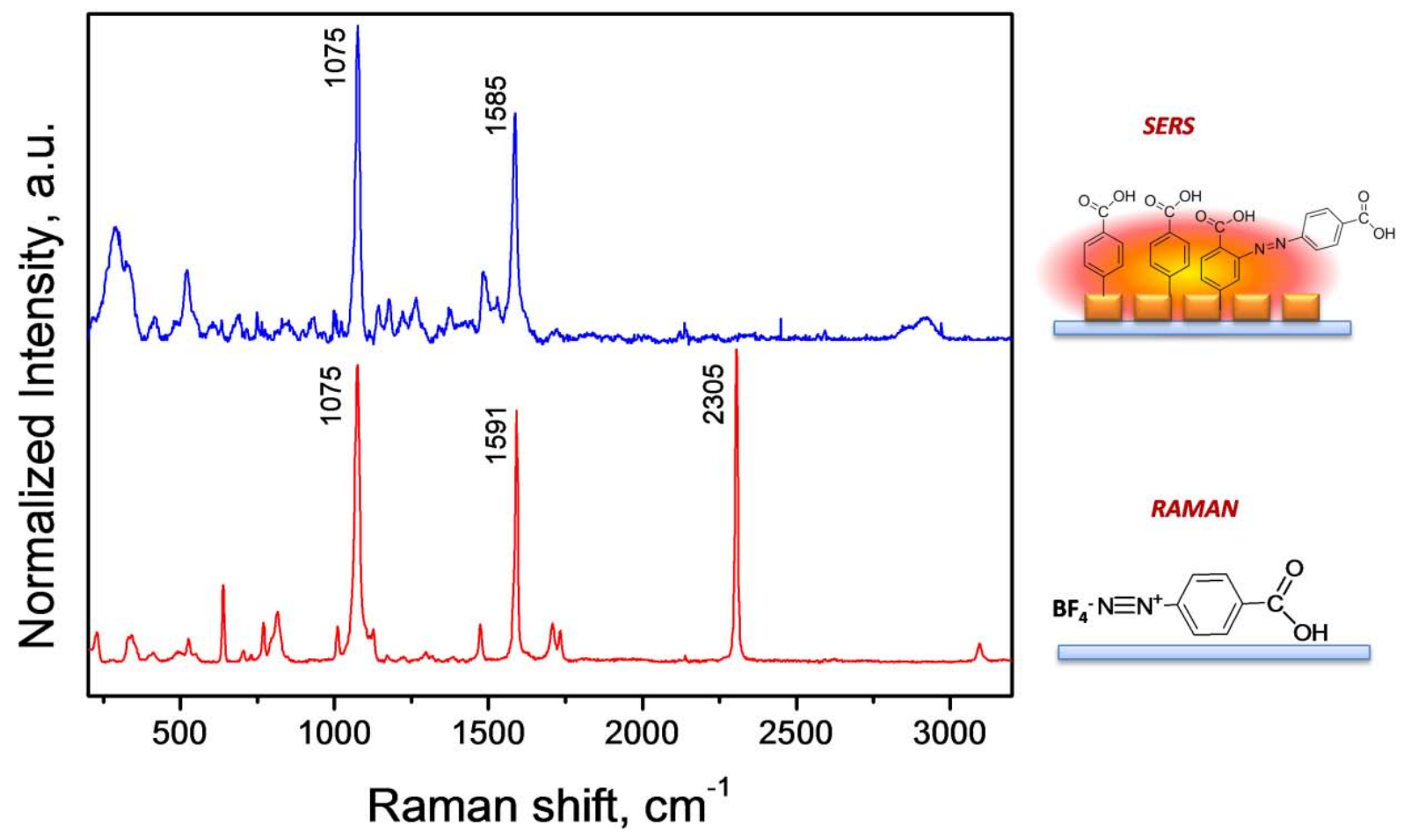

Figure 4: Raman spectrum of DS-COOH (red) and SERS spectrum of the DS-COOH-based GNS (blue). Each spectrum was normalized to its maximum intensity. Raman and SERS experiments were conducted at $691 \mathrm{~nm}$. SERS experiments used nano-cylinders with a diameter of $180 \mathrm{~nm}$. 


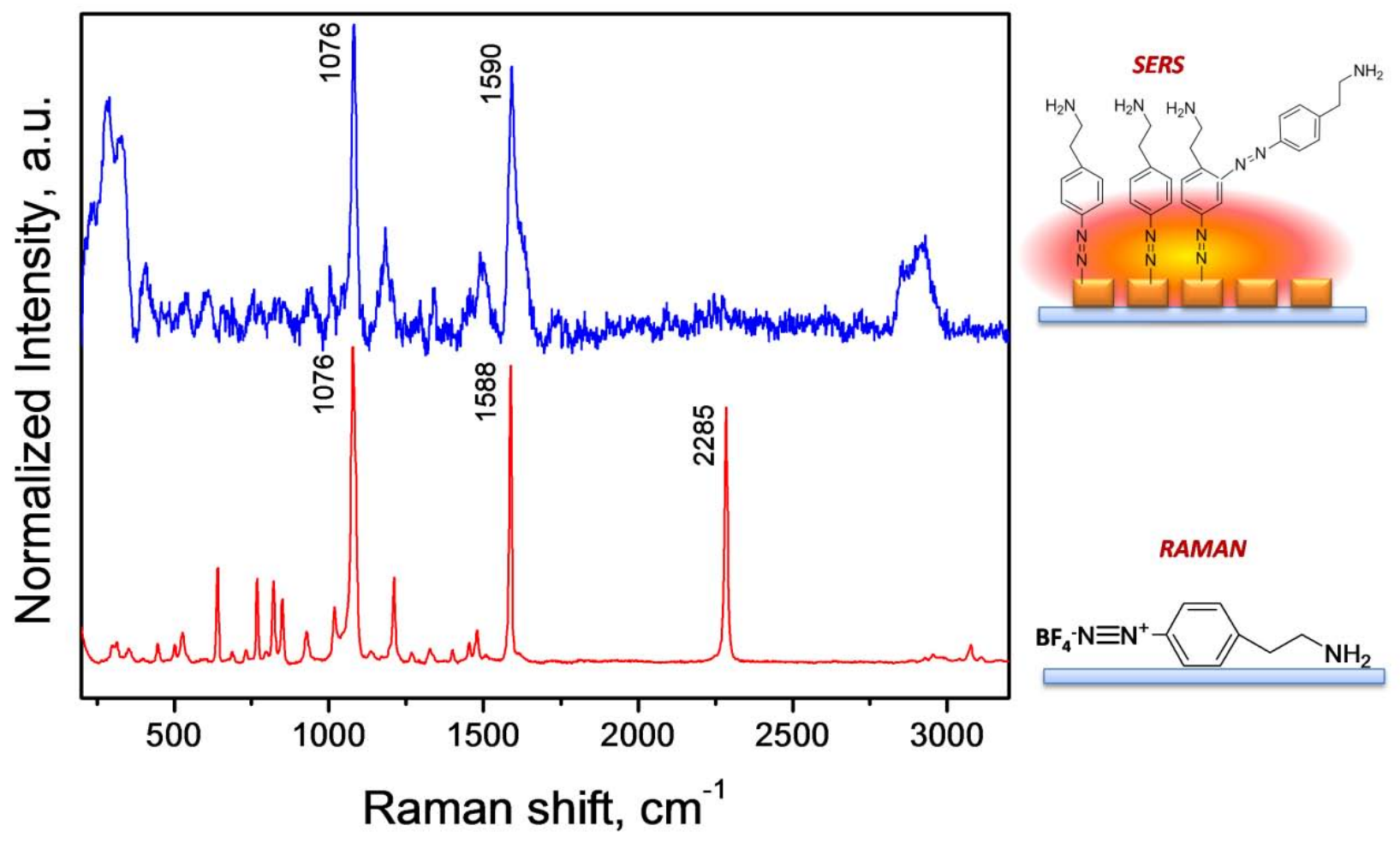

Figure 5: Raman spectrum of DS- $\left(\mathrm{CH}_{2}\right)_{2} \mathrm{NH}_{2}$ (red) and SERS spectrum of the DS- $\left(\mathrm{CH}_{2}\right)_{2} \mathrm{NH}_{2-}$ based GNS (blue). Each spectrum was normalized to its maximum intensity. Raman and SERS experiments were conducted at $691 \mathrm{~nm}$. SERS experiments used nano-cylinders with a diameter of $180 \mathrm{~nm}$. 


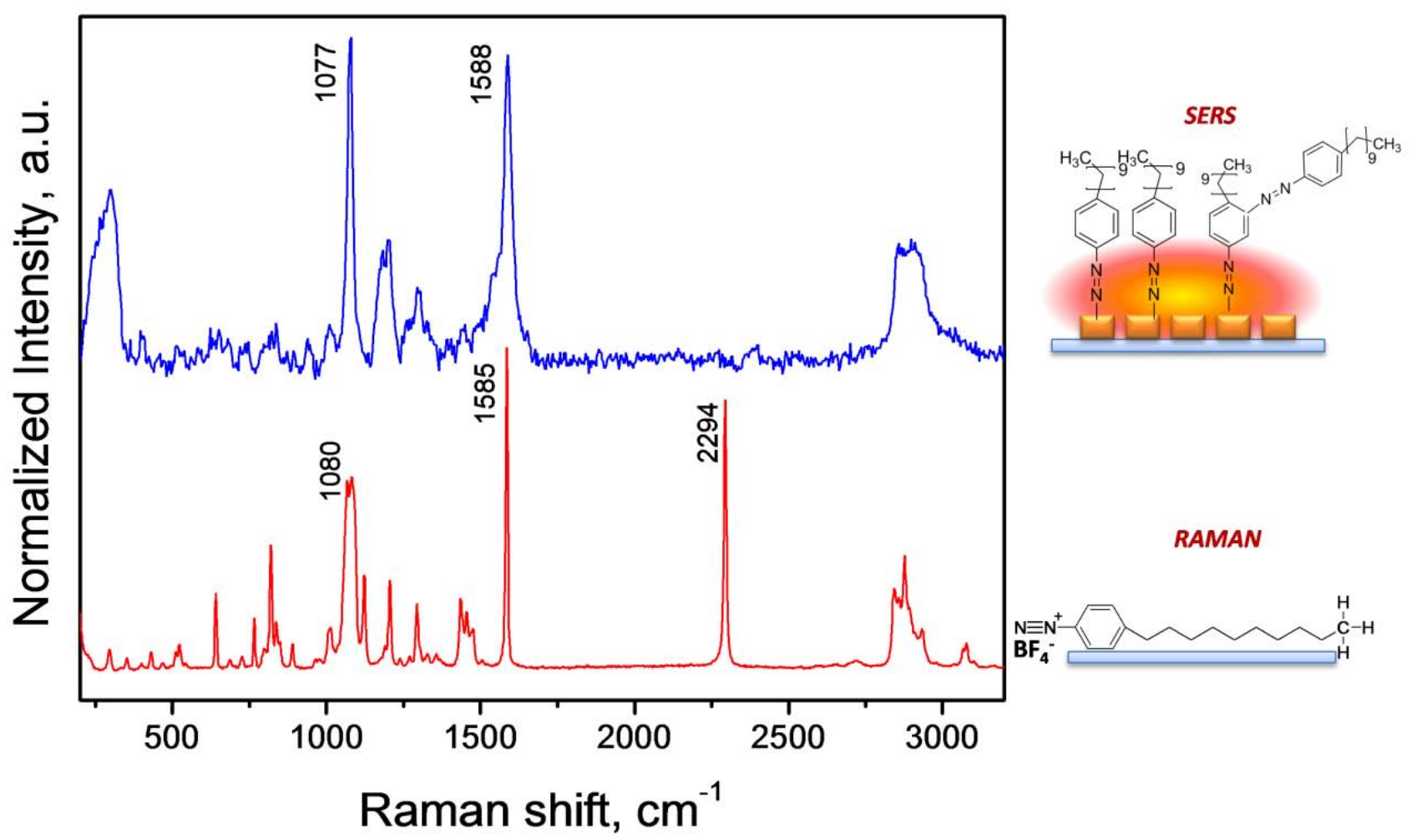

Figure 6: Raman spectrum of DS- $\mathrm{C}_{10} \mathrm{H}_{21}$ (red) and SERS spectrum of the DS- $\mathrm{C}_{10} \mathrm{H}_{21}$-based GNS (blue). Each spectrum was normalized to its maximum intensity. Raman and SERS experiments were conducted at $691 \mathrm{~nm}$. SERS experiments used nano-cylinders with a diameter of $180 \mathrm{~nm}$. 
Table 1: Band assignments for Raman and SERS spectra obtained for synthesized diazonium salts and grafted GNS. Raman shifts in cm ${ }^{-1}$.

\begin{tabular}{|c|c|c|c|c|c|c|c|c|}
\hline \multicolumn{4}{|c|}{ Synthesized diazonium salt } & \multicolumn{4}{|c|}{ Grafted GNS } & \multirow[t]{2}{*}{ Assignment } \\
\hline DS & $\begin{array}{c}\text { DS- } \\
\mathrm{COOH}\end{array}$ & $\begin{array}{c}\text { DS- } \\
(\mathrm{CH} 2)_{2} \mathrm{NH}_{2}\end{array}$ & $\begin{array}{c}\text { DS- } \\
\mathrm{C}_{10} \mathrm{H}_{21}\end{array}$ & DS & $\begin{array}{c}\text { DS- } \\
\mathrm{COOH}\end{array}$ & \begin{tabular}{c|} 
DS- \\
$(\mathrm{CH} 2)_{2} \mathrm{NH}_{2}$
\end{tabular} & $\begin{array}{c}\text { DS- } \\
\mathrm{C}_{10} \mathrm{H}_{21}\end{array}$ & \\
\hline 617 & 637 & 640 & 639 & & & & & Ring deformation ${ }^{54}$ \\
\hline 743 & & & & & & & & p CH wagging ${ }^{54-55}$ \\
\hline & 796 & 820 & 819 & & & & & o;m CH wagging ${ }^{54-55}$ \\
\hline & 814 & 849 & 837 & & & & & Ring breathing ${ }^{54}$ \\
\hline $\begin{array}{l}997 \\
1021\end{array}$ & & & & 999 & & & & $\begin{array}{l}\text { Ring deformation + ring breathing for benzene } \\
\text { and mono-substituted derivates }{ }^{5-55} \\
\text { CC stretching vibration }{ }^{56-57}\end{array}$ \\
\hline 1073 & 1075 & 1076 & 1080 & 1072 & 1075 & 1076 & 1077 & $\begin{array}{l}\mathrm{CH} \text { in plane bending for } \mathrm{p} \text { - and mono- } \\
\text { substituted benzenes }{ }^{22,55}\end{array}$ \\
\hline & & 1082 & 1079 & & & & & C-C stretching (aliphatic chain) ${ }^{55}$ \\
\hline
\end{tabular}




\begin{tabular}{|c|c|c|c|c|c|c|c|c|}
\hline 1162 & & & & 1138 & & & & $\mathrm{~m} ; \mathrm{p} \mathrm{CH}$ in plane bending ${ }^{54-55}$ \\
\hline \multirow[t]{2}{*}{1174} & $1170 \mathrm{vw}$ & $1198 \mathrm{vw}$ & $1190 \mathrm{vw}$ & 1182 & $1177 \mathrm{vw}$ & $1183 \mathrm{vw}$ & $1180 \mathrm{vw}$ & $\mathrm{m} ; \mathrm{o} \mathrm{CH}$ in plane bending ${ }^{54-55}$ \\
\hline & & 1454 & 1456 & & & & & $\mathrm{CH}_{2}$ scissoring ${ }^{58}$ \\
\hline \multirow[t]{2}{*}{1570} & 1591 & 1588 & 1585 & 1577 & 1585 & 1590 & 1588 & $\mathrm{C}=\mathrm{C}$ stretching ${ }^{54}$ \\
\hline & 1708 & & & & 1708 & & & $\mathrm{C}=\mathrm{O}$ stretching ${ }^{55}$ \\
\hline \multirow[t]{2}{*}{2296} & 2305 & 2285 & 2294 & & & & & $\mathrm{~N} \equiv \mathrm{N}$ stretching ${ }^{54-55}$ \\
\hline & & $2813-2986$ & $2813-$ & & & $2813-2956$ & $2815-$ & $\begin{array}{l}\text { Symmetric and anti-symmetric } \mathrm{CH} \text { stretch of } \mathrm{n} \text { - } \\
\text { alkanes }{ }^{55}\end{array}$ \\
\hline 3087 & 3096 & 3076 & $\begin{array}{l}3066 \\
3077\end{array}$ & & & & & Aromatic $\mathrm{CH}$ stretch of benzene derivative ${ }^{54-55}$ \\
\hline
\end{tabular}


Further comparison between the Raman spectra of the diazonium salts and the SERS spectra of the grafted GNS shows the main vibrational modes of interest.

First of all, the observation of strong peaks at 2296, 2305, 2285 and $2294 \mathrm{~cm}^{-1}$ for DS, DS$\mathrm{COOH}$, DS- $\left(\mathrm{CH}_{2}\right)_{2} \mathrm{NH}_{2}$ and $\mathrm{DS}-\mathrm{C}_{10} \mathrm{H}_{21}$, respectively (red spectra on Figures 3, 4, 5 and 6; Table 1), on the Raman spectra confirmed the occurrence of an $\mathrm{N} \equiv \mathrm{N}$ bond, in agreement with the specifics of the diazonium salts ${ }^{22,55}$. The most significant signature of the benzene ring was its ortho-meta $\mathrm{C}=\mathrm{C}$ stretching mode (Table 1 ) recorded in the range $1570-1591 \mathrm{~cm}^{-1} 56$. Finally, the undisputable signature of phenyl-derivatives stemming from diazonium salts was observed in the $1073-1080 \mathrm{~cm}^{-1}$ range $\left(1073,1075,1076\right.$ and $1080 \mathrm{~cm}^{-1}$, respectively, for DS, DS-COOH, DS$\left(\mathrm{CH}_{2}\right)_{2} \mathrm{NH}_{2}$ and DS- $\left.\mathrm{C}_{10} \mathrm{H}_{21}\right)$. This signature was assigned to $\mathrm{CH}$ in plane bending (coupled with ring-N stretching mode) for mono- and para-substituted benzenes (red spectra on Figures 3, 4, 5 and 6; Table 1; Figures S1, S2, S3 and S4). Compared with the Raman spectra of the amines (Figures S1, S2, S3 and S4), this characteristic band has been assigned to the electron-charge density redistribution into the structure caused by the presence of $\mathrm{N}_{2}{ }^{+}$, which is the strongest known electron acceptor ${ }^{59}$. Concerning DS-COOH, comparison between Raman experiments and DFT modeling showed that it is self-organized as dimers in the crystalline state ${ }^{41}$.

The successful grafting of GNS by diazonium salts was demonstrated by comparing the Raman spectra obtained for synthesized diazonium salts (red spectra on Figures 3, 4, 5 and 6) and the SERS spectra of the grafted ones (blue spectra on Figures 3, 4, 5 and 6). The absence on SERS spectra (blue spectra on Figures 3, 4, 5 and 6) of the strong peaks seen at 2296, 2305, 2285 and $2294 \mathrm{~cm}^{-1}$ for DS, DS-COOH, DS- $\left(\mathrm{CH}_{2}\right)_{2} \mathrm{NH}_{2}$ and DS- $\mathrm{C}_{10} \mathrm{H}_{21}$, respectively, on the Raman spectra of the salts and assigned to the $\mathrm{N} \equiv \mathrm{N}$ stretching (red spectra on Figures 3, 4, 5 and 6; Table 1) gave the first proof of efficient grafting. 
The strong band related to the stretching modes of aromatic ortho-meta $\mathrm{C}=\mathrm{C}^{56}$ (Table 1) can be seen on the SERS spectra in the range $1577-1590 \mathrm{~cm}^{-1}$. In the case of grafted GNS, this vibration is one of the modes preferentially enhanced through modification of the selection rules in SERS ${ }^{60}$, as vibrational modes involving a large change of polarization perpendicular to the metal surface are the most enhanced. In SERS spectra (blue spectra on Figures 3, 4, 5 and 6), a shoulder is also seen at the higher frequency side of this band. This peak overlapping with a slight shift can be assigned to the vibration of other aromatic ortho-meta $\mathrm{C}=\mathrm{C}$ present in the layer(s) above. The later aromatic ortho-meta $\mathrm{C}=\mathrm{C}$ vibration band can be differentiated from the same one grafted onto the gold interface because of their different respective vicinities, i.e. the former is part of the first layer grafted onto the GNS interface whereas the latter is part of the layer(s) above that are covalently linked to the former. The decrease in intensity of the overlapped peak can be attributed to the exaltation range, following Willets and Duyne (2007) ${ }^{61}$, who showed a real decrease in SERS intensity at the nanometer scale versus the distance from metallic nano-particles. It can also be assigned to SERS selection rules in agreement with Hallmark et Campion (1986) ${ }^{60}$, due to the growth of the layer in the meta position, which implies an inclination angle for the second aromatic ring with respect to the first one grafted perpendicularly onto the GNS.

Concerning the $\mathrm{C}=\mathrm{C}-\mathrm{C}$ related vibrations, two intensive peaks assigned to ring deformation and breathing modes for benzene and mono-substituted derivatives are only seen in the Raman spectrum of DS at around $997 \mathrm{~cm}^{-1}$ (Figure 3; Table 1, trigonal ring breathing vibration) and $1021 \mathrm{~cm}^{-1}$ (Figure 3; Table 1, CC stretching vibration coupled with $\mathrm{CH}$ in planebending vibration) ${ }^{56}$. For DS-based GNS (in SERS), one weak peak is seen at $999 \mathrm{~cm}^{-1}$, but in the case of para-substituted diazonium salts, these vibrational modes are not seen ${ }^{55}$. 
Bands assigned to ring deformation $(\mathrm{C}=\mathrm{C}-\mathrm{C}$ in plane deformation) in the region of 617$640 \mathrm{~cm}^{-1}$ (Table 1) are detectable for all diazonium salts. In agreement with Socrates ${ }^{55}$, such bands shift towards a higher wave-number for para-substituted aromatic compounds when compared to mono-substituted compounds, but they are no longer seen in SERS spectra. Similar observations can be made for the ring-deformation mode ${ }^{54}$ of para-substituted diazonium salts (Table 1, 814-849 $\mathrm{cm}^{-1}$ ).

Of particular interest is the very strong band related to $\mathrm{CH}$ in plane bending for mono- and para-substituted benzenes (coupled with ring-N stretching mode), observed between 1070 and $1080 \mathrm{~cm}^{-1}$ in diazonium salts and grafted GNS spectra (Figures 3, 4, 5 and 6, and Table 1). SERS enhancement of this latter mode suggests that the chemosorbed molecules have adopted a perpendicular orientation with respect to the Au surface ${ }^{62}$, in agreement with the previous observation for ring-deformation mode detected at $1585 \mathrm{~cm}^{-1}$. This assumption is further confirmed by the presence of both m,o-CH in plane-bending mode at $1177-1179 \mathrm{~cm}^{-1}$, seen for all grafted phenyl derivatives, and m,p-CH in plane-bending mode in the range $1138-1162 \mathrm{~cm}^{-1}$ (Table 1) for DS and DS-based GNS.

Concerning the different para functions carried by the aromatic cycle (i.e. - $\mathrm{COOH}$, $\left(\mathrm{CH}_{2}\right)_{2} \mathrm{NH}_{2}$ and $\left.-\mathrm{C}_{10} \mathrm{H}_{21}\right)$, some characteristic bands have been identified. For diazonium salts carrying $\left(\mathrm{CH}_{2}\right)_{2} \mathrm{NH}_{2}$ or $\mathrm{C}_{10} \mathrm{H}_{21}$, the symmetric and asymmetric $\mathrm{CH}_{3}$ stretching modes of $\mathrm{n}$ alkanes as well as the symmetric $\mathrm{CH}_{2}$ stretching mode of n-alkanes are clearly identified in the region $2813-2986 \mathrm{~cm}^{-1}$ (Table 1). In addition, a C-C stretching mode in the $1079-1082 \mathrm{~cm}^{-1}$ region (Table 1); and a $\mathrm{CH}_{2}$ scissoring mode in the region $1454-1456 \mathrm{~cm}^{-1}$ (Table 1) were also observed. The intensity of the latter bands is strongly reduced in SERS spectra of grafted GNS; this might be due to larger a distance of such chemical groups from the gold surface, in 
agreement with the results by Willets and Duyne (2007) ${ }^{61}$, leading to less enhanced Raman modes of such groups when compared to the ring modes. Concerning DS-COOH (Fig. 4, Table 1), the weak to very weak bands observed at 1708 and $1732 \mathrm{~cm}^{-1}$ are characteristic features of the carboxylic group due to $\mathrm{C}=\mathrm{O}$ symmetric and asymmetric stretching vibrations, respectively. In agreement with DFT modeling ${ }^{41}$, this result supports the presence of dimer structures into the crystal packing (DS-COOH); i.e., dimer structures included into the crystal packing have a lower symmetry, leading to both $v_{\text {sym }}(\mathrm{C}=\mathrm{O})_{\text {dimer }}$ and $v_{\text {asym }}(\mathrm{C}=\mathrm{O})_{\text {dimer }}$ becoming Raman active. With regard to DS-COOH-based GNS, a very weak band is seen at $1708 \mathrm{~cm}^{-1}$, agreeing with the fact that grafted $\mathrm{COOH}$ features a center of symmetry, imposing the mutual exclusion rule for vibrational modes. In this framework, the $v_{\mathrm{sym}}(\mathrm{C}=\mathrm{O})$ is Raman active, while $v_{\text {asym }}(\mathrm{C}=\mathrm{O})$ is Raman inactive.

Comparison of the diazonium-salt Raman spectra and the SERS spectra of the functionalized GNS shows that chemical grafting occurred. Whatever the investigated phenyl derivative, the most characteristic bands are the strong ones related to: (i) the aromatic ring deformations found in the range of $1570-1591 \mathrm{~cm}^{-1}$, and (ii) the $\mathrm{CH}$ in plane bending for monoand para-substituted benzenes (coupled with ring-N stretching mode) found in the range 1075$1074 \mathrm{~cm}^{-1}$. At this stage, SERS enhancement of these two bands confirms the perpendicular orientation of the aromatic rings on the GNS. Nevertheless, the SERS measurements do not help in identifying the nature of the covalent bonding atom $(\mathrm{C}$ or $\mathrm{N})$ between gold and the aromatic rings. Thus, in order to clarify this point, further investigations were conducted by XPS. 


\section{XPS Investigations}

In order to examine the nature of the interface between gold surface and coating, XPS measurements were performed on flat gold thin-films functionalized through spontaneous grafting in the same way as for GNS. All recorded spectra were calibrated versus the Au4f peak.

High-resolution XPS (HR-XPS) Au4f, C1s and N1s spectra were investigated for each coating. Figure 7 shows HR-XPS spectra of the C1s region recorded for the DS-COOH-based coating, whereas Figure 8 shows the N1s region obtained for each coating.

As stated in the literature ${ }^{63}$, observation of the Au-C bond by XPS remained a challenge due to the insignificant difference in electro-negativity between carbon and gold atoms $(\chi \mathrm{c}=$ 2.55 and $\chi \mathrm{Au}=2.54$, using the Pauling scale).

For the DS-COOH-based coating (Fig. 7), the C1s region showed three components at $284.6 \mathrm{eV}, 286.0 \mathrm{eV}$ and $288.7 \mathrm{eV}$, assigned to the $\mathrm{CC} / \mathrm{CH}, \mathrm{C}-\mathrm{O}$, and $\mathrm{COOH}$ groups, respectively.

For the N1s region (Fig. 8), the broad peaks observed in the range 396-403 eV can be fitted into two or three peaks, depending on the nature of the coating. The N1s core provided by DS-, DS- $\left(\mathrm{CH}_{2}\right)_{2} \mathrm{NH}_{2}$ - and DS- $\mathrm{C}_{10} \mathrm{H}_{21}$-based coatings can be fitted into three peaks, whereas the one provided by DS-COOH can be decomposed into two peaks. Gold nitrides (Au-N) ${ }^{36}$ were found at $398.0 \mathrm{eV}$ for DS, DS- $\left(\mathrm{CH}_{2}\right)_{2} \mathrm{NH}_{2}$ and DS- $\mathrm{C}_{10} \mathrm{H}_{21}$. On the contrary, according to the literature ${ }^{36}$, no $\mathrm{Au}-\mathrm{N}$ bonds were observed in the spectra provided by DS-COOH-based coating. The presence of azo groups $(\mathrm{N}=\mathrm{N}){ }^{36,64-65}$ was found for each coating at $400.2 \mathrm{eV}$. The last fitted peak at $399.5 \mathrm{eV}$ for each spectrum was assigned to the presence of $\mathrm{NH}_{2}$, following the literature ${ }^{36}$, and possibly NH. The latter peak would be expected for a DS- $\left(\mathrm{CH}_{2}\right)_{2}-\mathrm{NH}_{2}$-based coating. The fact that it was recorded for each coating may mean that the presence of an $\mathrm{NH}_{2}$ and/or -NH-NHgroup is driven by $-\mathrm{N}=\mathrm{N}$ - (radiation-sensitive functional group) decomposition under the beam. 
A similar effect is known from electrochemistry using 4-bromophenyldiazonium salt ${ }^{66-67}$; $-\mathrm{N}=\mathrm{N}-$ exposure to X-ray irradiation may be an alternate pathway for explaining the presence of $\mathrm{NH}_{2}$ and/or -NH-NH- groups in the coatings.

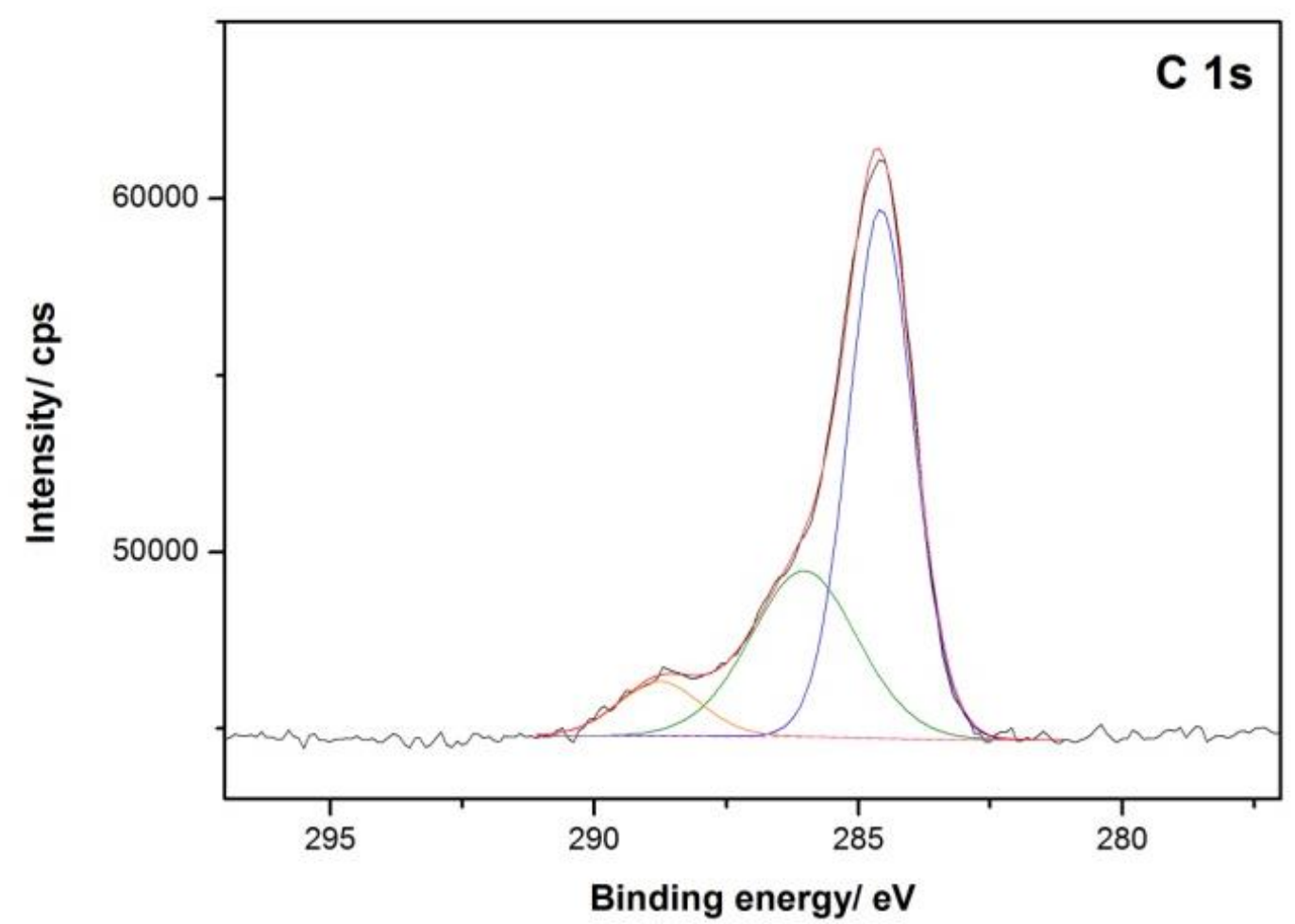

Figure 7: HR-XPS spectra of the $\mathrm{C} 1$ s region recorded on the DS-COOH grafted on a flat gold surface. The overall fitted data are plotted as a red line. 


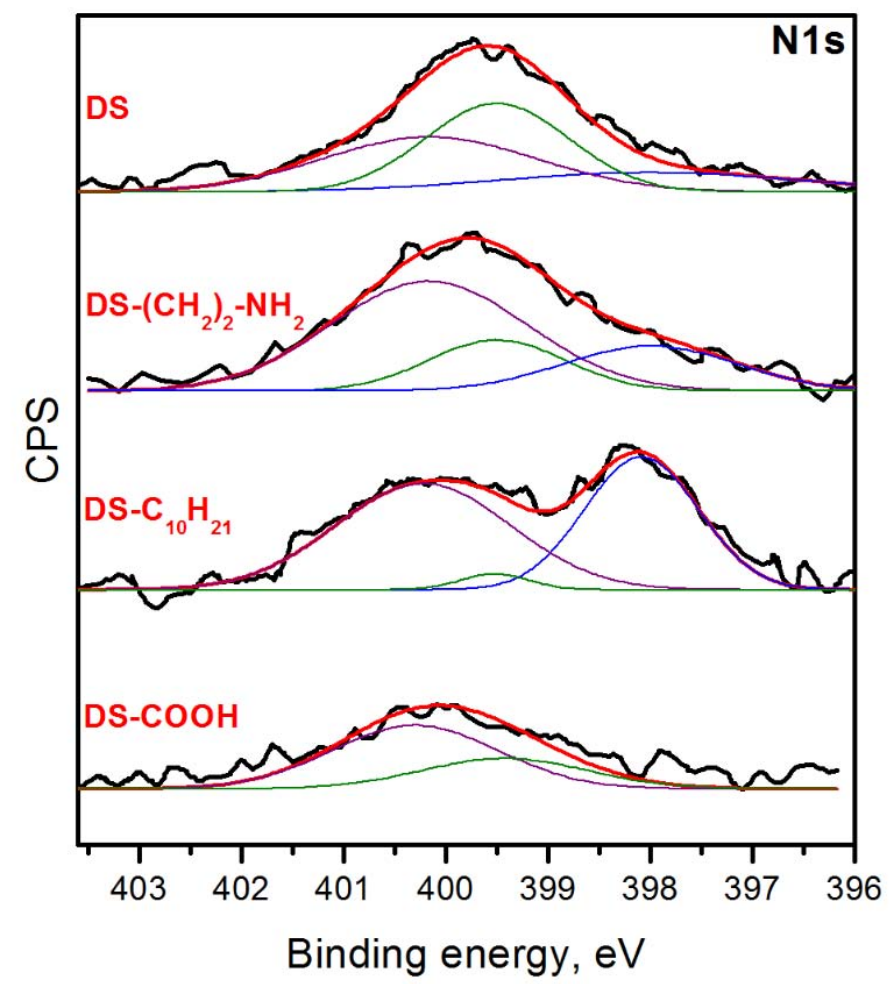

Figure 8: HR-XPS spectra of the N 1s region recorded on flat gold surfaces coated via DS, DS$\left(\mathrm{CH}_{2}\right)_{2} \mathrm{NH}_{2}, \mathrm{DS}-\mathrm{C}_{10} \mathrm{H}_{21}$ and DS-COOH. The overall fitted data are plotted as red lines.

The XPS results suggest that (under our operating conditions), when using DS, DS- $\left(\mathrm{CH}_{2}\right)_{2}$ $\mathrm{NH}_{2}$ and $\mathrm{DS}-\mathrm{C}_{10} \mathrm{H}_{21}$, a flat gold surface functionalization occurred via azophenyl radical pathways. More precisely, it was shown that: (i) the coatings are grafted at the interface via Au$\mathrm{N}$ bonds, and (ii) the multilayers are formed retaining $-\mathrm{N}=\mathrm{N}$ - groups (Fig. 1D). These results agree with the SERS results, without excluding the aryl radical pathways as illustrated on Figure 1E. For DS-COOH, the results provided by XPS demonstrate an effective grafting onto the gold surface via aryl radicals (as was documented earlier ${ }^{36}{ }^{22}$ ). The presence of $-\mathrm{N}=\mathrm{N}-$ groups on the layers is supported by the direct bond in meta position to an aromatic ring already attached to the conductive surface (Fig. 1E), but it is worth noting that aryl radical pathways, such as illustrated by Figure 1B, cannot be excluded. 


\section{DFT Modelling}

In order to gain further insight into the grafted layer and to confirm both SERS spectra and XPS interpretations (especially the presence of $\mathrm{N}=\mathrm{N}$ groups onto the coating), DFT calculations were performed on DS-COOH-based GNS (Figures 9 and S5). The spontaneous de-diazonation leading to a carboxyphenyl-gold adduct with formation of an Au-C bond was modeled by DFT as $\mathrm{CB}-\mathrm{Au}$. A second mechanism leading to azo adducts with the formation of an $\mathrm{Au}-\mathrm{N}$ bond was modeled and named CB- $\mathrm{N}_{2}-\mathrm{Au}$. In our case, given that, after incubation of GNS in the DS$\mathrm{COOH}$ solution, the functionalized platform was washed several times with water at neutral $\mathrm{pH}$, the resulting carboxyphenyl layer is likely in the carboxylate form. Therefore, the possible presence of deprotonated monolayers was also modeled as CBoate-Au and CBoate- $\mathrm{N}_{2}-\mathrm{Au}$.

In addition to the monolayer on a gold surface model, the grafted multilayers of aryl groups were also considered using biphenyl adducts on gold. (see Supporting Information Figure S5) ${ }^{65}$.

Confrontation of the experimental SERS spectrum with the various simulated spectra has shown that the CB-Au model does not reproduce most of the Raman features in the experimental spectrum. Moreover, the latter model agrees with the assumptions deriving from XPS results, i.e. no Au-N bonds have been observed in the spectra provided by DS-COOH-based coated flat gold. Moreover, the characteristic strong band predicted by DFT at $1720 \mathrm{~cm}^{-1}$ and corresponding to the $\mathrm{C}=\mathrm{O}$ stretching mode $v(\mathrm{C}=\mathrm{O})$, is quasi absent in the experimental SERS spectrum. It is worth noting that the latter result agrees with the literature on SERS experiments on the adsorbed benzoate that exhibits a rather weak $\mathrm{C}=\mathrm{O}$ stretching band ${ }^{68-70}$. In this sense, the stretching mode $v(\mathrm{C}=\mathrm{O})$ is absent in the simulated deprotonated monolayer CBoate-Au spectra. The CBoate-Au 
model appears to be the best for reproducing the spectral characteristics of the experimental SERS spectrum in terms of both position and intensity of the bands.
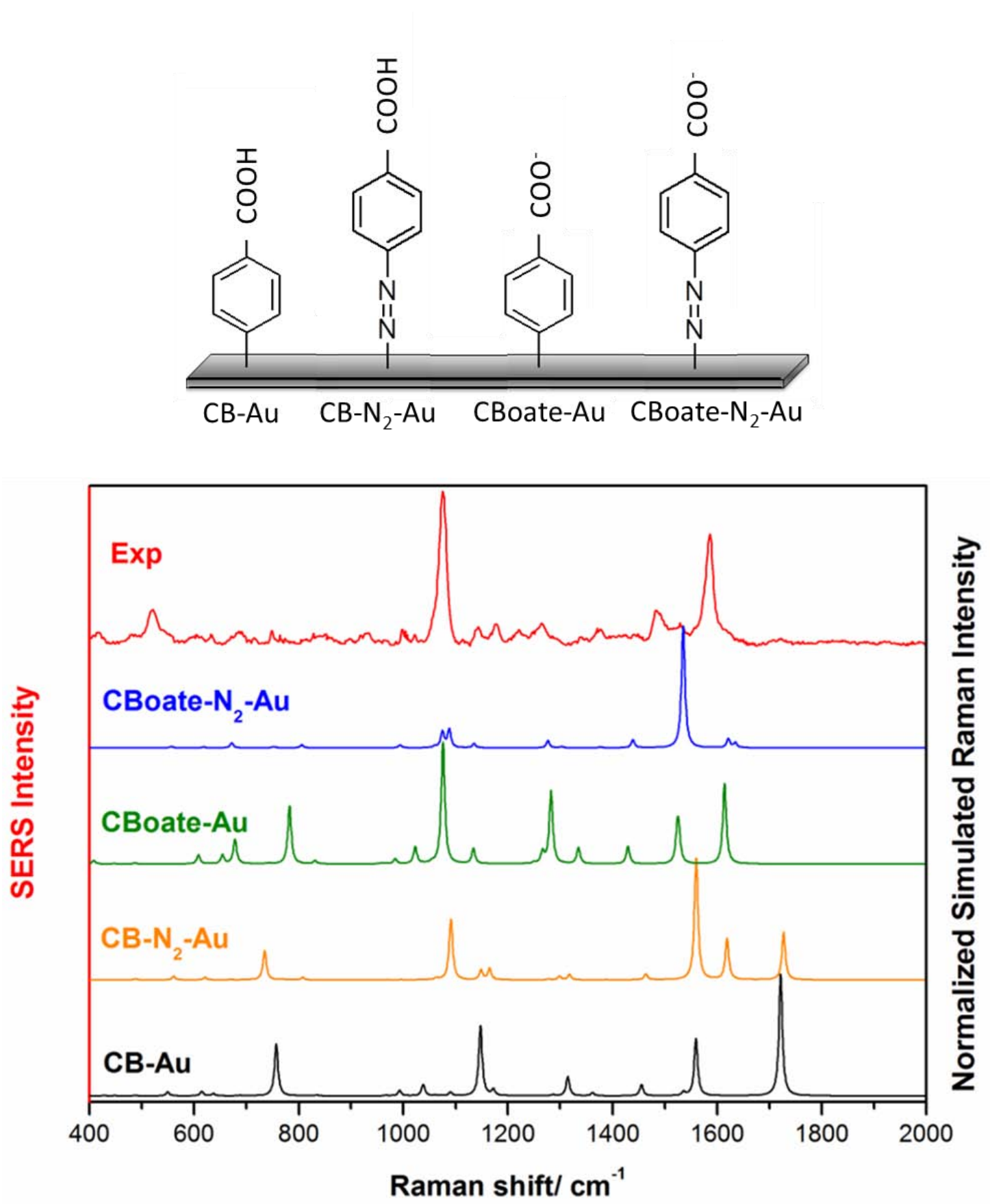

Figure 9: Comparison of the experimental SERS spectrum recorded for DS-COOH with the spectra obtained by DFT modeling for different adducts. 
The results provided by DFT thus demonstrate that, under the experimental conditions, the effective chemical grafting of the GNS is realized via a covalent bond between gold and carboxylate forms. Modeling further supports that the growth of multilayers can be accomplished in the meta position via either an $-\mathrm{N}=\mathrm{N}$ - bond or a $\mathrm{C}-\mathrm{C}$ bond between the aromatic rings.

\section{Conclusions}

The effective chemical grafting of four different phenyl derivatives on GNS was demonstrated by SERS through: (i) the absence of the characteristic $\mathrm{N} \equiv \mathrm{N}$ group vibration band and (ii) the presence of the characteristic bands of diazonium salts. The observation of aromatic ring deformation found in the range of $1570-1591 \mathrm{~cm}^{-1}$ as well as of the $\mathrm{CH}$ in plane bending for mono- and para-substituted benzenes (coupled with ring-N stretching mode) at around $1075 \mathrm{~cm}^{-1}$ provides irrefutable evidence of such grafting and suggests a perpendicular orientation of the aromatic rings on the GNS.

In agreement with the results provided by SERS, XPS results measured on a flat gold surface suggest azophenyl radical pathways for the chemical grafting of the gold surface by using DS, DS- $\mathrm{C}_{10} \mathrm{H}_{21}$, or DS- $\left(\mathrm{CH}_{2}\right)_{2}-\mathrm{NH}_{2}$. Such a mechanism is involved in the coating at the interface (via Au-N bond), as well as in the growth of layers (via an $\mathrm{N}=\mathrm{N}$ bond). For DS-COOH, the results provided by SERS, XPS and DFT calculation demonstrate: (i) the effective chemical grafting of GNS via a covalent bond between gold and carboxylate forms, and (ii) the growth of multilayers in the meta position between aromatic rings, through either $-\mathrm{N}=\mathrm{N}$ - and/or $\mathrm{C}-\mathrm{C}$ bonds. 


\section{Author Information}

\section{Corresponding Author}

* Stéphanie Betelu, BRGM, Water, Environment and Eco-technology Division, 45060 Orléans

Cedex 02, France, +332386432 68, s.betelu@brgm.fr

\section{Author Contributions}

$\$$ These authors contributed equally

\section{Acknowledgments}

This work was funded by the ANR ECOTECH (Production durable et technologies de l'environnement) REMANTAS project: Enhanced Raman scattering for aquatic media: a new technology for on-site analysis 2012-2016 (REMANTAS project (ANR-11-ECOT-0010)). 


\section{References}

1. Young, M. A.; Stuart, D. A.; Lyandres, O.; Glucksberg, M. R.; Van Duyne, R. P. Surface-Enhanced Raman Spectroscopy with a Laser Pointer Light Source and Miniature Spectrometer. Can. J. Chem. 2004, 82, 1435-1441.

2. Otto, A.; Mrozek, I.; Grabhorn, H.; Akemann, W. Surface-Enhanced Raman Scattering. J. Phys.: Condens. Matter 1992, 4, 1143-1212.

3. Peron, O.; Rinnert, E.; Lehaitre, M.; Crassous, P.; Compere, C. Detection of Polycyclic Aromatic Hydrocarbon (PAH) Compounds in Artificial Sea-Water Using Surface-Enhanced Raman Scattering (SERS). Talanta 2009, 79, 199-204.

4. Peron, O.; Rinnert, E.; Florent, C.; Lehaitre, M.; Compere, C. First Steps of in Situ Surface-Enhanced Raman Scattering During Shipboard Experiments. Appl. Spectrosc. 2010, 64, 1086-1093.

5. Peron, O.; Rinnert, E.; Toury, T.; Lamy de la Chapelle, M.; Compère, C. Quantitative SERS Sensors for Environmental Analysis of Naphthalene. Analyst 2011, 136, 1018-1022.

6. Prien, R. D. The Future of Chemical in Situ Sensors. Mar. Chem. 2007, 107, 422-432.

7. Rogers, J. A.; Jackman, R. J.; Whitesides, G. M. Constructing Single- and MultipleHelical Microcoils and Characterizing Their Performance as Components of Microinductors and Microelectromagnets. J. Microelectromech. Syst. 1997, 6, 184-192.

8. Ulman, A. Formation and Structure of Self-Assembled Monolayers. Chem. Rev. 1996, 96, 1533-1554.

9. Zielinski, O.; Busch, J. A.; Cembella, A. D.; Daly, K. L.; Engelbrektsson, J.; Hannides, A. K.; Schmidt, H. Detecting Marine Hazardous Substances and Organisms: Sensors for Pollutants, Toxins, and Pathogens. Ocean Sci. 2009, 6, 953-1005. 
10. Guillot, N.; Lamy de la Chapelle, M. Lithographied Nanostructures as Nanosensors. $J$. Nanophotonics 2012, 6, 064506:1-28.

11. David, C.; Guillot, N.; Shen, H.; Toury, T.; Lamy de la Chapelle, M. SERS Detection of Biomolecules Using Lithographed Nanoparticles Towards a Reproducible SERS Biosensor. Nanotechnology 2010, 21, 475-501.

12. Shen, H.; Guillot, N.; Rouxel, J.; Lamy de la Chapelle, M.; Toury, T. Optimized Plasmonic Nanostructures for Improved Sensing Activities. Ppt. Express 2012, 20, 21278 21290.

13. Cottat, M.; Lidgi-Guigui, N.; Hamouda, F.; Bartenlian, B.; Venkataraman, D.; Marks, R. S.; Steele, T. W. J.; Lamy de la Chapelle, M. Highly Sensitive Detection of Paclitaxel by Surface Enhanced Raman Scattering. J. Opt. 2015, 17, 114019: 1-5.

14. Cottat, M.; D’Andrea, C.; Yasukuni, R.; Malashikhina, N.; Grinyte, R.; Lidgi-Guigui, N.; Fazio, B.; Sutton, A.; Oudar, O.; Charnaux, et al. High Sensitivity, High Selectivity SERS Detection of MnSOD Using Optical Nanoantennas Functionalized with Aptamers. J. Phys. Chem. C 2015, 119, 15532-15540.

15. Boujday, S.; Lamy de la Chapelle, M.; Srajer, J.; Knoll, W. Enhanced Vibrational Spectroscopies as Tools for Small Molecule Biosensing. Sensors 2015, 15 21239-21264.

16. Becker, A.; Tobias, H.; Porat, Z.; Mandler, D. Detection of Uranium(VI) in Aqueous Solution by a Calix[6]Arene Modified Electrode. J. Electroanal. Chem. 2008 621, 214-221.

17. Evans, C. J.; Nicholson, G. P. A Self-Assembled Electrochemical Sensor for Uranium. Sens. Actuators, B 2005, 105, 204-207.

18. Liu, G.; Bocking, T.; Gooding, J. J. Diazonium Salts: Stable Monolayers on Gold Electrodes for Sensing Applications. J. Electroanal. Chem. 2007, 600, 335-344. 
19. Adenier, A.; Cabet-Deliry, E.; Chaussé, A.; Griveau, S.; Mercier, F.; Pinson, J.; Vautrin-

Ul, C. Grafting of Nitrophenyl Groups on Carbon without Electrochemical Induction. Chem. Mater. 2005, 17, 491-501.

20. Bekyarova, E.; Itkis, M. E.; Ramesh, P.; Berger, C.; Sprinkle, M.; de Heer, W. A.; Haddon, R. C. Chemical Modification of Epitaxial Graphene: Spontaneous Grafting of Aryl Groups. J. Am. Chem. Soc. 2009, 131, 1336-1337.

21. Combellas, C. M.; Delamar, F.; Kanoufi, F.; Pinson, J.; Podvorica, F. I. Spontaneous Grafting of Iron Surfaces by Reduction of Aryldiazonium Salts in Acidic or Neutral Aqueous Solution. Application to the Protection of Iron against Corrosion. Chem. Mater. 2005, 17, 3968 3975.

22. Laurentius, L.; Stoyanov, S. R.; Gusarov, S.; Kovalenko, A.; Du, R.; Lopinski, G. P.; McDermott, M. T. Diazonium-Derived Aryl Films on Gold Nanoparticles: Evidence for a Carbon-Gold Covalent Bond. ACS Nano 2011, 5, 4219-4227.

23. Betelu, S.; Vautrin-Ul, C.; Chaussé, A. Novel 4-Carboxyphenyl-Grafted Screen-Printed Electrode for Trace Cu(Ii) Determination. Electrochem. Commun. 2009, 11, 383-386.

24. Betelu, S.; Vautrin-Ul, C.; Ly, J.; Chaussé, A. Screen-Printed Electrografted Electrode for Trace Uranium Analysis. Talanta 2009, 80, 372-376.

25. Delamar, M.; Hitmi, R.; Pinson, J.; Savéant, J. Covalent Modification of Carbon Surfaces by Grafting of Functionalized Aryl Radicals Produced from Electrochemical Reduction of Diazonium Salts. J. Am. Chem. Soc. 1992, 114, 5883-5884.

26. Bouriga, M.; Chehimi, M. M.; Combellas, C.; Decorse, P.; Kanoufi, F.; Deronzier, A.; Pinson, J. Sensitized Photografting of Diazonium Salts by Visible Light. Chem. Mater. 2013, 25, 90-97. 
27. Andrieux, C. P.; Pinson, J. The Standard Redox Potential of the Phenyl Radical/Anion Couple. J. Am. Chem. Soc. 2003, 125, 14801-14806.

28. Boukerma, K.; Chehimi, M. M.; Pinson, J.; Blomfield, C. X-Ray Photoelectron Spectroscopy Evidence for the Covalent Bond between an Iron Surface and Aryl Groups Attached by the Electrochemical Reduction of Diazonium Salts. Langmuir 2003, 19, 6333-6335.

29. Kariuki, J. K.; McDermott, M. T. Nucleation and Growth of Functionalized Aryl Films on Graphite Electrodes. Langmuir 1999, 15, 6534-6540.

30. Ricci, A. M.; Mendez De Leo, L. P.; Williams, F. J.; Calvo, E. J. Some Evidence for the Formation of an Azo Bond During the Electroreduction of Diazonium Salts on Au Substrates. ChemPhysChem 2012, 13, 2119-2127.

31. Laforgue, A.; Addou, T.; Bélanger, D. Characterization of the Deposition of Organic Molecules at the Surface of Gold by the Electrochemical Reduction of Aryldiazonium Cations. Langmuir 2005, 21, 6855-6865.

32. Saby, C.; Ortiz, B.; Champagne, G. Y.; Bélanger, D. Electrochemical Modification of Glassy Carbon Electrode Using Aromatic Diazonium Salts. 1. Blocking Effect of 4-Nitrophenyl and 4-Carboxyphenyl Groups. Langmuir 1997, 13 6805-6813.

33. Toupin, M.; Bélanger, D. Spontaneous Functionalization of Carbon Black by Reaction with 4-Nitrophenyldiazonium Cations. Langmuir 2008, 24, 1910-1917.

34. Combellas, C.; Kanoufi, F.; Pinson, J.; Podvorica, F. Sterically Hindered Diazonium Salts for the Grafting of a Monolayer on Metals. J. Am. Chem. Soc. 2008, 130, 8576-8577. 35. Jung, U.; Kuhn, S.; Cornelissen, U.; Tuczek, F.; Strunskus, T.; Zaporojtchenko, V.; Kubitschke, J.; Herges, R.; Magnussen, O. Azobenzene-Containing Triazatriangulenium 
Adlayers on $\mathrm{Au}(111)$ : Structural and Spectroscopic Characterization. Langmuir 2011, 27, 5899-

5908.

36. Mesnage, A.; Lef. vre, X.; Pascale, J.; Deniau, G.; Palacin, S. Spontaneous Grafting of Diazonium Salts: Chemical Mechanism on Metallic Surfaces. Langmuir 2012, 28, 11767-11778.

37. Bahr, J. L.; Yang, J.; Kosynkin, D. V.; Bronikowski, M. J.; Smalley, R. E.; Tour, J. M.

Functionalization of Carbon Nanotubes by Electrochemical Reduction of Aryl Diazonium Salts:

A Bucky Paper Electrode. J. Am. Chem. Soc. 2001, 123, 6536-6542.

38. Allongue, P.; Delamar, M.; Desbat, B.; Fagebaume, O.; Hitmi, R.; Pinson, J.; Savéant, J.

M. Covalent Modification of Carbon Surfaces by Aryl Radicals Generated from the

Electrochemical Reduction of Diazonium Salts. J. Am. Chem. Soc. 1997, 119, 201-207.

39. Murphy, T.; Schmidt, H.; Kronfeldt, H. D. Detection of Chemicals in Seawater Using

Surface-Enhanced Raman Scattering (SERS). Proc. SPIE 1997, 3107, 281-287.

40. Grand, J.; Kostcheev, S.; Bijeon, J. L.; Lamy de la Chapelle, M.; Adam, P. M.;

Rumyantseva A.; Lérondel, G.; Royer, P. Optimization of SERS-Active Substrates for near-

Field Raman Spectroscopy. Synth. Met. 2003, 139, 621-624.

41. Betelu, S.; Tijunelyte, I.; Boubekeur-Lecaque, L.; Ignatiadis, I.; Schnepf, A. C.; Guenin,

E.; Bouchemal, N.; Félidj, N.; Rinnert, E.; Lamy de la Chapelle, M. Raman Characterization of

Phenyl-Derivatives: From Primary Amine to Diazonium Salts. Spectrochim. Acta, Part A 2016,

Submitted manuscript.

42. Guillot, N.; de la Chapelle, M. L. The Electromagnetic Effect in Surface Enhanced Raman Scattering: Enhancement Optimization Using Precisely Controlled Nanostructures. $J$.

Quant. Spectrosc. Radiat. Transfer 2012, 113, 2321-2333. 
43. Billot, L.; Lamy de la Chapelle, M.; Grimault, A.; Vial, A.; Barchiesi, D.; Bijeon, J.; Adam, P.; Royer, P. Surface Enhanced Raman Scattering on Gold Nanowire Arrays: Evidence of Strong Multipolar Surface Plasmon Resonance Enhancement. Chem. Phys. Lett. 2006, 422, 303307.

44. Grimault, A.; Vial, A.; Lamy de la Chapelle, M. Modeling of Regular Gold Nanostructures Arrays for SERS Applications Using a 3d Fdtd Method. Appl. Phys. B: Lasers Opt. 2006, 84, 111-115.

45. Grand, J.; Lamy de la Chapelle, M.; Bijeon, J. L.; Adam, P. M.; Vial, A.; Royer, P. Role of Localized Surface Plasmons in Surface Enhanced Raman Scattering of Shape-Controlled Metallic Particles in Regular Arrays. Phys. Rev. B 2005, 72, 033407: 1-4.

46. Guillot, N.; Shen, H.; Fremaux, B.; Péron, O.; Rinnert, E.; Toury, T.; Lamy de la Chapelle, M. Surface Enhanced Raman Scattering Optimization of Gold Nanocylinder Arrays: Influence of the Localized Surface Plasmon Resonance and Excitation Wavelength. Appl. Phys. Lett. 2010, 97, 023113: 1-3.

47. R. A, Frisch, M. J.; Trucks, G. W.; Schlegel, H. B.; Scuseria, G. E.; Robb, M. A.; Cheeseman, J. R.; Scalmani, G.; Barone, V.; Mennucci, B.; Petersson, G. A. et al. Gaussian 09; Gaussian, Inc.: Wallingford, CT, 2009.

48. Becke, A. D. Density-Functional Thermochemistry. III. The Role of Exact Exchange. $J$. Chem. Phys. 1993, 98, 5648-5652.

49. Lee, C.; Yang, W.; Parr, R. G. Development of the Colle-Salvetti Correlation-Energy Formula into a Functional of the Electron Density. Phys. Rev. B 1988, 37, 785-789. 
50. Clark, T.; Chandrasekhar, J.; Spitznagel, G. W.; Schleyer, P. V. R. Efficient Diffuse Function-Augmented Basis Sets for Anion Calculations. III. The 3-21+G Basis Set for FirstRow Elements, Li-F. J. Comput. Chem. 1983, 4, 294-301.

51. Francl, M. M.; Pietro, W. J.; Hehre, W. J.; Binkley, J. S.; Gordon, M. S.; Defrees, D. J.; Pople, J. A. Self-Consistent Molecular Orbital Methods. 23. A Polarization Basis Set for Second Row Elements. J. Chem. Phys. 1982, 77, 3654-3665.

52. Hay, P. J.; Wadt, W. R. Ab Initio Effective Core Potentials for Molecular Calculations. Potentials for the Transition-Metal Atoms Sc to Hg. J. Chem. Phys. 1985, 82, 270-283

53. Fairchild, S. Z.; Bradshaw, C. F.; Su, W.; Guharay, S. K. Predicting Raman Spectra Using Density Functional Theory. Appl. Spectrosc. 2009, 63, 733-741.

54. Badawi, H. M.; Förner, W.; Ali, S. A Comparative Study of the Infrared and Raman Spectra of Aniline and O-, M-, P-Phenylenediamine Isomers. Spectrochim. Acta, Part A 2013, $112,388-396$.

55. Socrates, G. Infrared and Raman Characteristic Group Frequencies: Tables and Charts (Third Edition), Chichester (U.K.) ed.; J. Wiley \& Sons: West Sussex, 2001.

56. Wojciechowski, P. M.; Zierkiewicz, W.; Michalska, D.; Hobza, P. Electronic Structures, Vibrational Spectra, and Revised Assignment of Aniline and Its Radical Cation: Theoretical Study. J. Chem. Phys. 2003, 118, 10900-10911.

57. Badawi, H. M. A Comparative Study of the Structure and Vibrational Spectra of Diphenylmethane, the Carcinogen 4,4'-Methylenedianiline and 4,4'-Methylenebis(N,NDimethylaniline). Spectrochim. Acta, Part A 2013, 109, 213-220.

58. Venkateswaran, C. S.; Pandya, N. S. The Raman Spectra of Organic Compounds: Diethyl Disulphide. Proc. Indian Acad. Sci., A 1942, 15, 396-400. 
59. Zollinger, H. Diazo Chemistry: Aromatic and Heteroaromatic Compounds, Volume 1:

New York 1994.

60. Hallmark, V.; Campion, A. Selection Rules for Surface Raman Spectroscopy:

Experimental Results J. Chem. Phys. 1986, 84, 2933-2941.

61. K.A.Willets; Duyne, R. P. V. Localized Surface Plasmon Resonance Spectroscopy and Sensing. Annu. Rev. Phys. Chem. 2007, 58, 267-297.

62. Baia, M.; Baia, L.; Kiefer, W.; Popp, J. Surface-Enhanced Raman Scattering and Density Functional Theoretical Study of Anthranil Adsorbed on Colloidal Silver Particles. J. Phys. Chem. B 2004, 108, 17491-17496.

63. Ahmad, R.; Mocaer, A.; Gam-Derouich, S.; Lamouri, A.; Lecoq, H.; Decorse, P.; Brunet,

P.; Mangeney, C. Grafting of Polymeric Platforms on Gold by Combining the Diazonium Salt Chemistry and the Photoiniferter Method. Polymer 2015, 57, 12-20.

64. Doppelt, P.; Pinson, J.; Podvorica, F.; Verneyre, S.; Hallais, G. Surface Modification of Conducting Substrates. Existence of Azo Bonds in the Structure of Organic Layers Obtained from Diazonium Salts Chem. Mater. 2007, 19, 4570-4575.

65. Ahmad, R.; Boubekeur-Lecaque, L.; Nguyen, M.; Lau-Truong, S.; Lamouri, A.; Decorse, P.; Galtayries, A.; Pinson, J.; Felidj, N.; Mangeney, C. Tailoring the Surface Chemistry of Gold Nanorods through $\mathrm{Au}-\mathrm{C} / \mathrm{Ag}-\mathrm{C}$ Covalent Bonds Using Aryl Diazonium Salts. J. Phys. Chem. C 2014, 118, 19098-19105.

66. Actis, P.; Caulliez, G.; Shul, G.; Opallo, M.; Mermoux, M.; Marcus, B.; Boukherroub, R.; Szunerits, S. Functionalization of Glassy Carbon with Diazonium Salts in Ionic Liquids. Langmuir 2008, 24, 6327-6333. 
67. Ullien, D.; Thune, P. C.; Jager, W. F.; Sudholter, E. J. R.; de Smeta, L. C. P. M. Controlled Amino-Functionalization by Electrochemical Reduction of Bromo and Nitro Azobenzene Layers Bound to Si(111) Surfaces. Phys. Chem. Chem. Phys. 2014, 16, 1925819265.

68. Kwon, Y. J.; Son, D. H.; Ahn, S. J.; Kim, M. S.; Kim, K. Vibrational Spectroscopic Investigation of Benzoic Acid Adsorbed on Silver. J. Phys. Chem. C 1994, 98, 8481-8487.

69. Moskovits, M.; Suh, J. S. Surface Geometry Change in 2-Naphthoic Acid Adsorbed on Silver. J. Phys. Chem. C 1988, 92, 6327-6329.

70. Yu, K. H.; Rhee, J. M.; Lee, Y.; Lee, K.; Yu, S. C. Surface-Enhanced Raman Scattering Study of 4-Biphenylcarboxylic Acid. Langmuir 2001, 17, 52-55. 


\section{Table of Contents (TOC) Image}

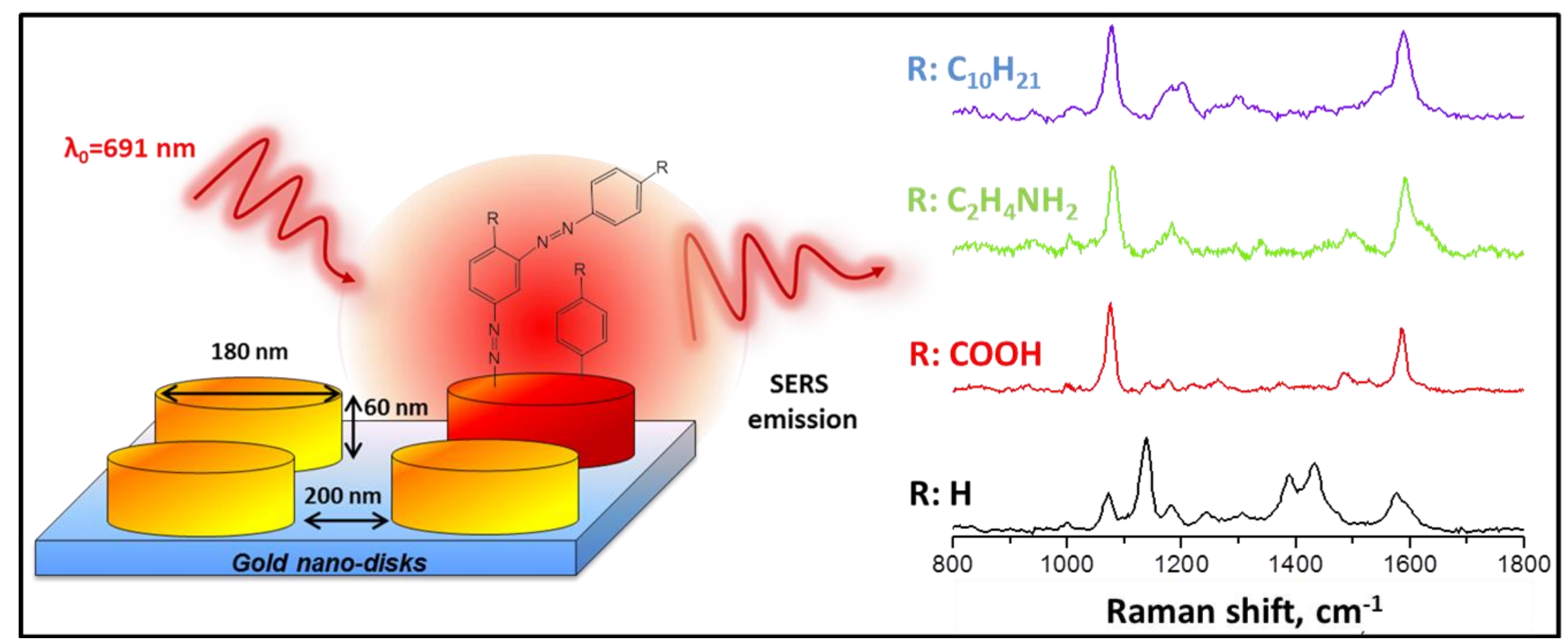




\section{Electronic supplementary information}

\section{Evidence of the Grafting Mechanisms of Diazonium Salts on Gold}

\section{Nanostructures}

Stéphanie Betelu, ${ }^{1 *}$ Inga Tijunelyte, ${ }^{2 \ddagger}$ Leïla Boubekeur-Lecaque, ${ }^{3 \ddagger}$ Ioannis Ignatiadis, ${ }^{1}$ Joyce Ibrahim, ${ }^{4}$ Stéphane Gaboreau, ${ }^{1}$ Catherine Berho, ${ }^{1}$ Timothée Toury, ${ }^{3}$ Erwann Guenin, ${ }^{2}$ Nathalie Lidgi-Guigui, ${ }^{2}$ Nordin Félidj, ${ }^{3}$ Emmanuel Rinnert, ${ }^{5}$ Marc Lamy de la Chapelle, ${ }^{2}$

${ }^{1}$ BRGM, Water, Environment and Eco-technology Division / Laboratory Direction, F-45060 OrléansCedex 02, France

${ }^{2}$ University Paris13, Sorbonne Paris Cité, Laboratoire CSPBAT, CNRS, (UMR7244), 74 rue Marcel Cachin, 93017 Bobigny, France

${ }^{3}$ University Paris Diderot, Sorbonne Paris Cité, ITODYS, UMR 7086 CNRS, 15 rue J-A de Baïf, 75205 Paris Cedex 13, France

${ }^{4}$ University of Technology of Troyes (UTT), 12, rue Marie Curie, 10000 Troyes, France ${ }^{5}$ IFREMER, Brittany center, Measurements, Detection and Sensors Laboratory, CS10070, 29280 Plouzané, France 


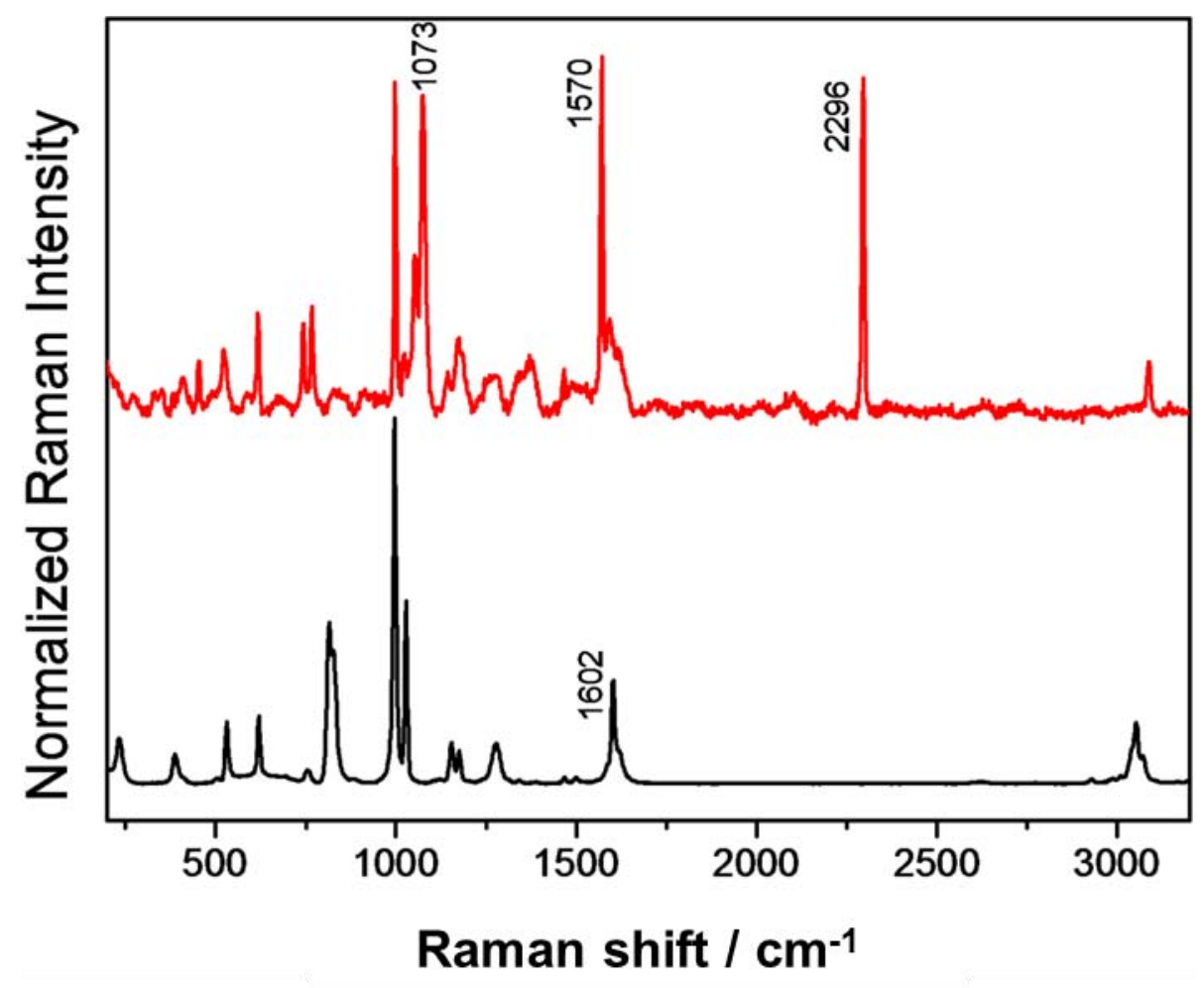

Figure S1: Raman spectra of aniline (black spectrum) and the corresponding diazonium salt: benzenediazoniumtetrafluoroborate, DS (red spectrum). Each spectrum was normalized to its maximum intensity. 


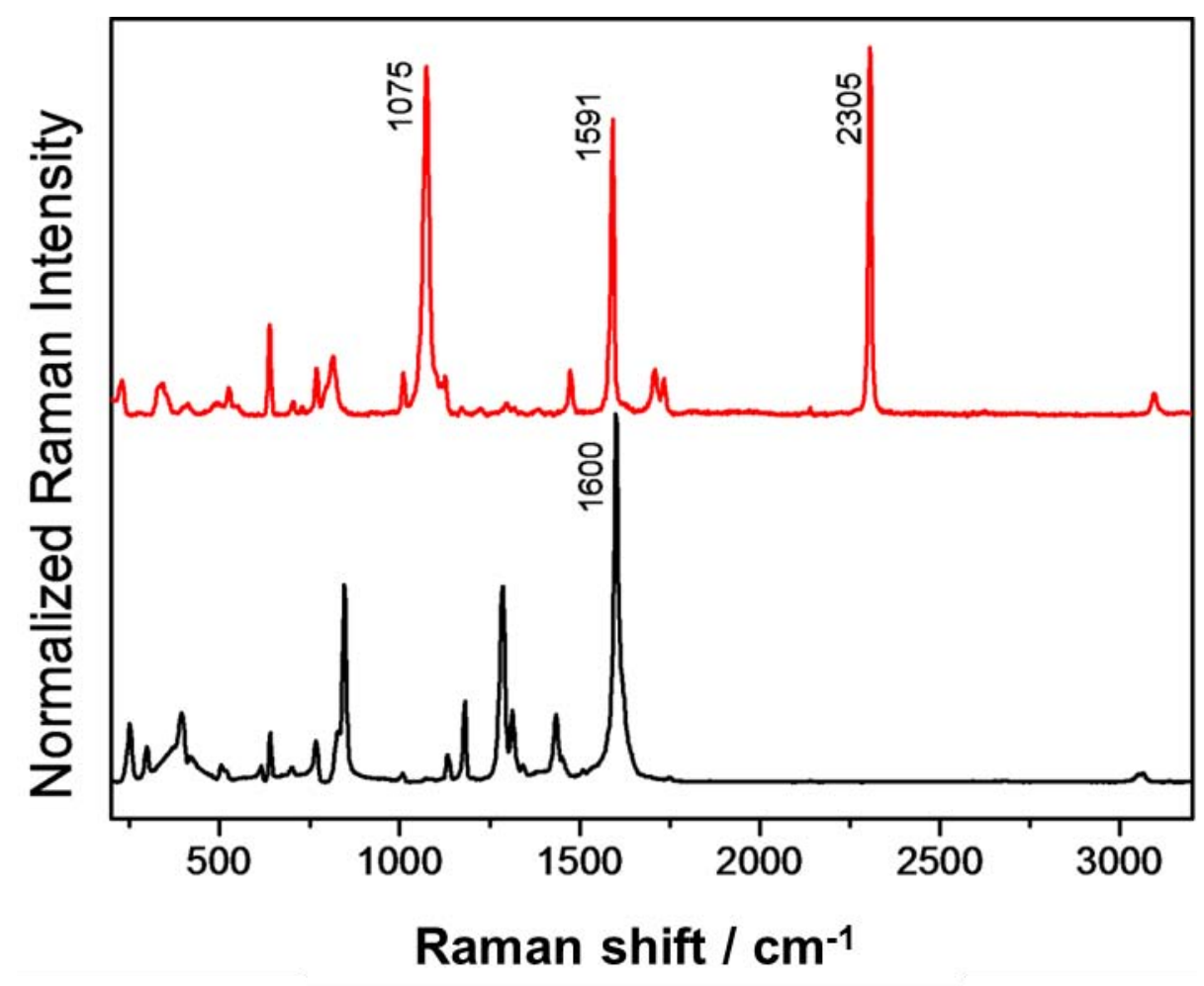

Figure S2: Raman spectra of 4-aminobenzoic acid (black spectrum) and the corresponding diazonium salt: 4-carboxybenzene diazoniumtetrafluoroborate, DS-COOH (red spectrum). Each spectrum was normalized to its maximum intensity. 


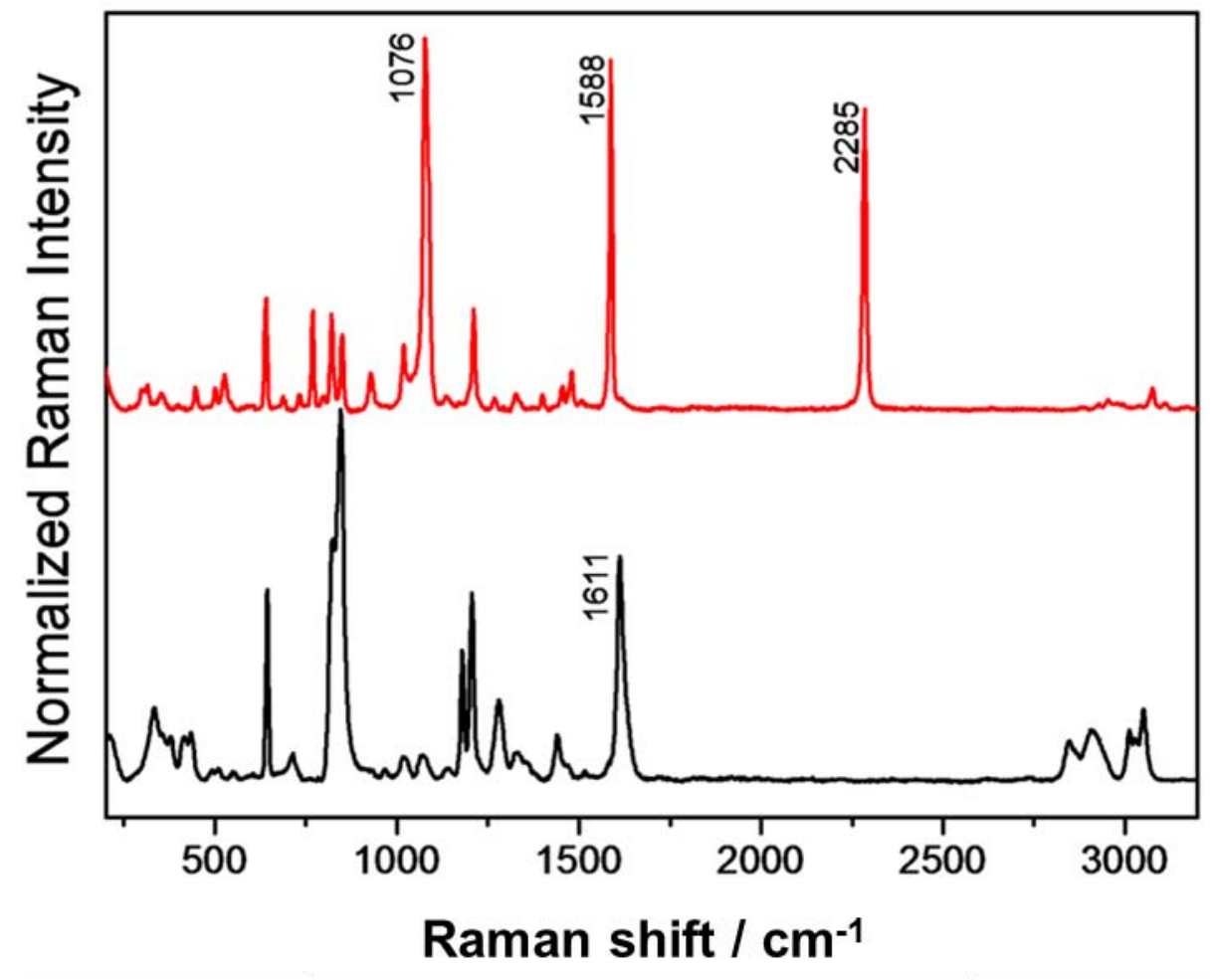

Figure S3: Raman spectra of 4-(2-Aminoethyl)aniline (black spectrum) and the corresponding diazonium salt: DS- $\left(\mathrm{CH}_{2}\right)_{2} \mathrm{NH}_{2}$ (red spectrum). Each spectrum was normalized to its maximum intensity. 


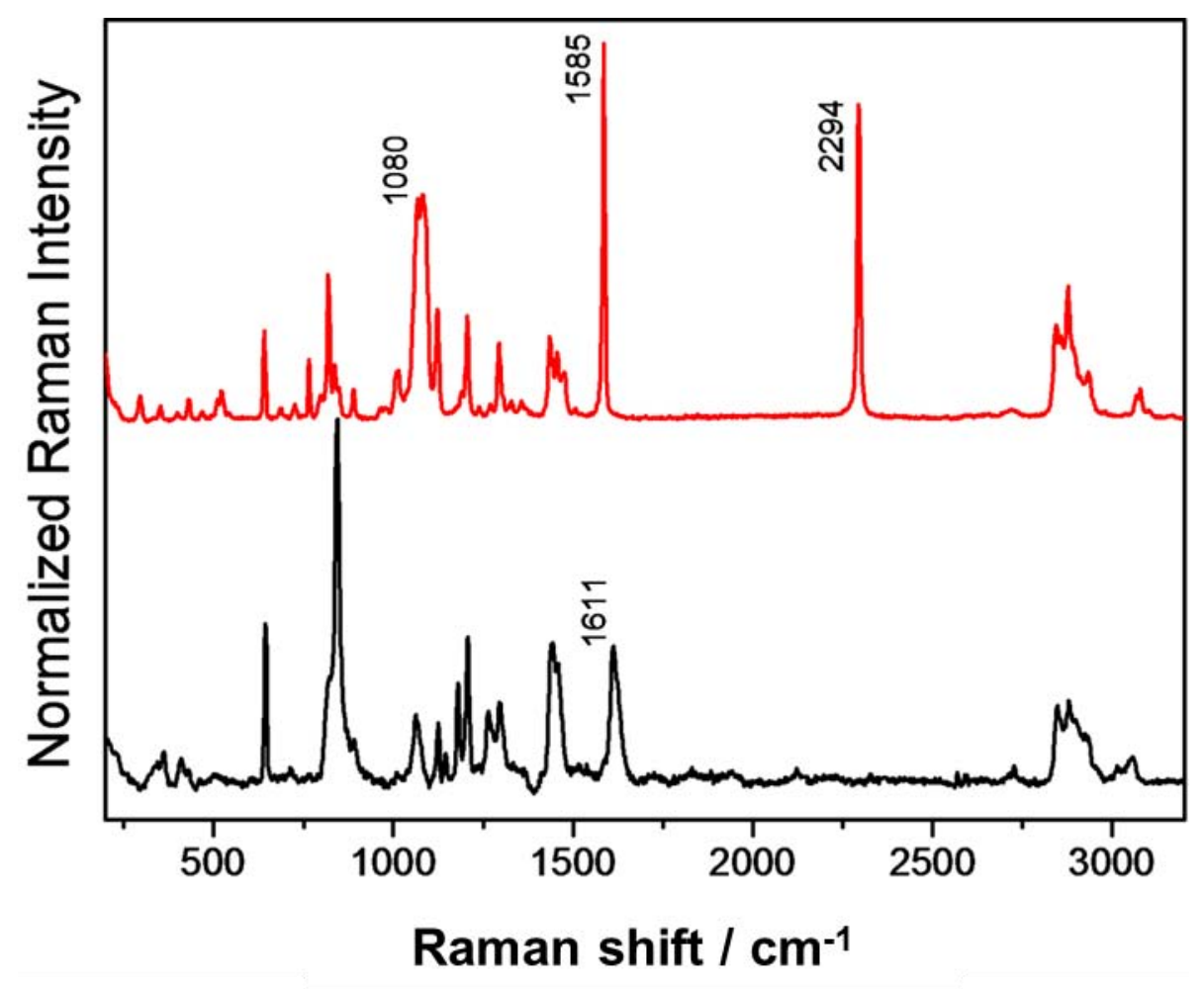

Figure S4: Raman spectra of 4-decylaniline (black spectrum) and the corresponding diazonium salt: 4-decyl benzenediazoniumtetrafluoroborate, $\mathrm{DS}-\mathrm{C}_{10} \mathrm{H}_{21}$ (red spectrum). Each spectrum was normalized to its maximum intensity. 


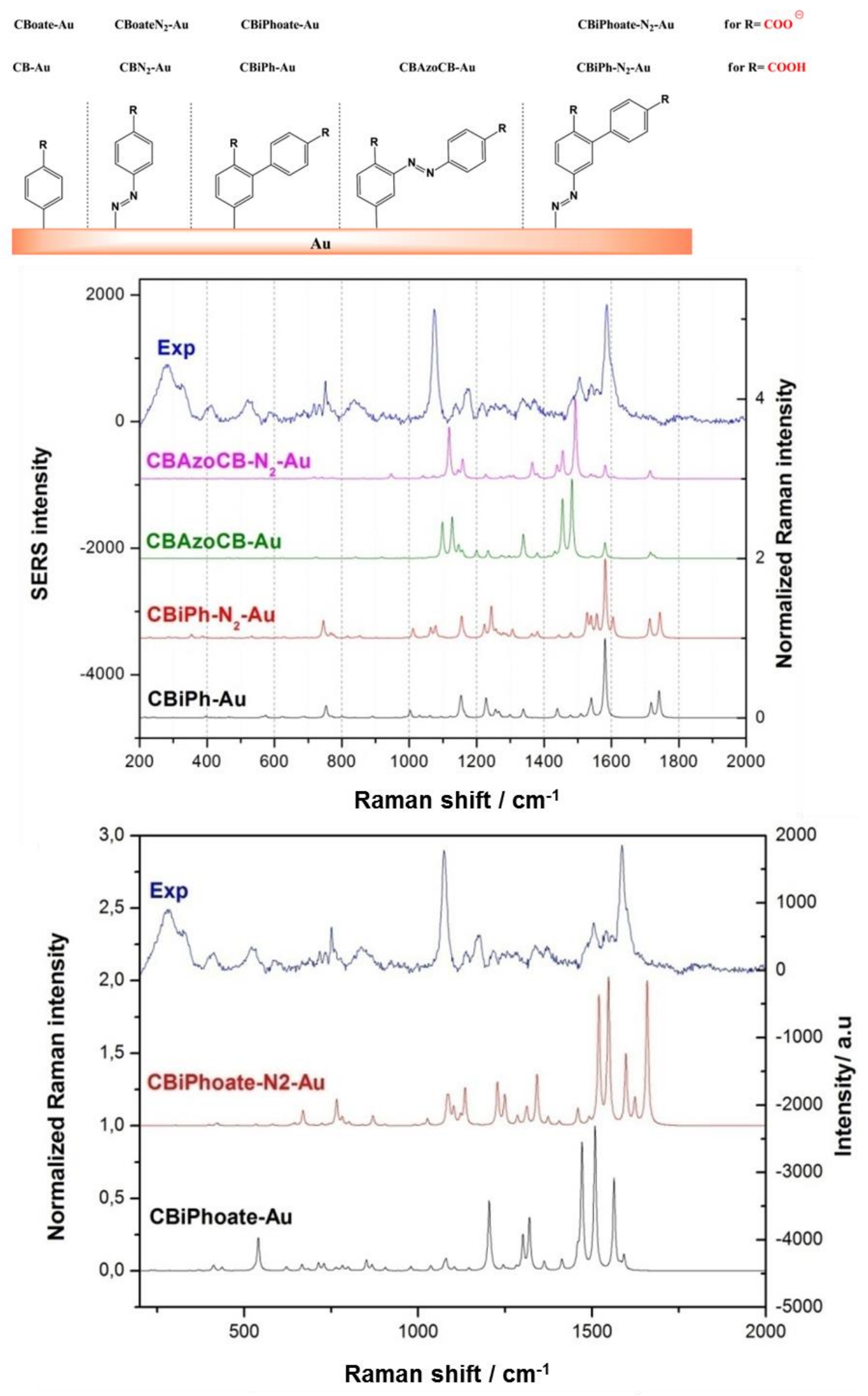

Figure S5: Additional DS-COOH adducts envisaged for DFT modeling. 


\section{Full citations for references 14 and 47}

14. Cottat, M.; D’Andrea, C.; Yasukuni, R.; Malashikhina, N.; Grinyte, R.; Lidgi-Guigui, N.; Fazio, B.; Sutton, A.; Oudar, O.; Charnaux, N.; Pavlov, V.; Toma, A.; Di Fabrizio, E.; Gucciardi, P. G.; Lamy de la Chapelle, M. High Sensitivity, High Selectivity Sers Detection of MnSOD Using Optical Nanoantennas Functionalized with Aptamers. J. Phys. Chem. C 2015, 119, 15532-15540.

47. R. A, Frisch, M. J.; Trucks, G. W.; Schlegel, H. B.; Scuseria, G. E.; Robb, M. A.; Cheeseman, J. R.; Scalmani, G.; Barone, V.; Mennucci, B.; Petersson, G. A.; Nakatsuji, H.; Caricato, M.; Li, X.; Hratchian, H. P.; Izmaylov, A. F.; Bloino, J.; Zheng, G.; Sonnenberg, J. L.; Hada, M.; Ehara, M.; Toyota, K.; Fukuda, R.; Hasegawa, J.; Ishida, M.; Nakajima, T.; Honda, Y.; Kitao, O.; Nakai, H.; Vreven, T.; Montgomery, Jr., J. A.; Peralta, J. E.; Ogliaro, F.; Bearpark, M.; Heyd, J.J.; Brothers, E.; Kudin, K. N.; Staroverov, V. N.; Kobayashi, R.; Normand, J.; Raghavachari, K.; Rendell, A.; Burant, J. C.; Iyengar, S. S.; Tomasi, J.; Cossi, M.; Rega, N.; Millam, J. M.; Klene, M.; Knox, J. E.; Cross, J. B.; Bakken, V.; Adamo, C.; Jaramillo, J.; Gomperts, R.; Stratmann, R. E.; Yazyev, O.; Austin, A. J.; Cammi, R.; Pomelli, C.; Ochterski, J. W.; Martin, R. L.; Morokuma, K.; Zakrzewski, V. G.; Voth, G. A.; Salvador, P.; Dannenberg, J. J.; Dapprich, S.; Daniels, A. D.; Farkas, . .; Foresman, J. B.; Ortiz, J. V.; Cioslowski, J.; Fox, D. J. Gaussian 09; Gaussian, Inc.: Wallingford, CT, 2009. 